\title{
Creep Burst Testing of a Woven Inflatable Module
}

\author{
Molly M. Selig ${ }^{1}$, Gerard D. Valle ${ }^{2}$, and George H. James ${ }^{3}$ \\ NASA Johnson Space Center, Houston, TX 77058 \\ Ovidio M. Oliveras ${ }^{4}$ \\ Jacobs Engineering, Houston, TX 77058 \\ and \\ Thomas C. Jones ${ }^{5}$, William R. Doggett ${ }^{6}$ \\ NASA Langley Research Center, Hampton, VA 23681
}

\begin{abstract}
A woven Vectran inflatable module 88 inches in diameter and 10 feet long was tested at the NASA Johnson Space Center until failure from creep. The module was pressurized pneumatically to an internal pressure of 145 psig, and was held at pressure until burst. The external environment remained at standard atmospheric temperature and pressure. The module burst occurred after $\mathbf{4 9}$ minutes at the target pressure. The test article pressure and temperature were monitored, and video footage of the burst was captured at 60 FPS. Photogrammetry was used to obtain strain measurements of some of the webbing. Accelerometers on the test article measured the dynamic response. This paper discusses the test article, test setup, predictions, observations, photogrammetry technique and strain results, structural dynamics methods and quick-look results, and a comparison of the module level creep behavior to the strap level creep behavior.
\end{abstract}

\section{Nomenclature}

a $=$ distance from the torus axis of revolution to the centerline of the circular cross-section

$\mathrm{b}=$ radius of the torus circular cross section

${ }^{\circ} \mathrm{F} \quad=$ degrees Fahrenheit

FPS $=$ frames per second

$\mathrm{ft} \quad=$ foot

$\mathrm{g}=$ gravity

$\mathrm{GN} 2=$ gaseous nitrogen

in $\quad=$ inch

JSC $=$ Johnson Space Center

$\mathrm{L}_{1} \quad=$ length of each axial strap

$\log =$ logarithmic

$\mathrm{n}_{1} \quad=$ number of axial straps

$\mathrm{n}_{2} \quad=$ number of hoop straps

NASA $=$ National Aeronautics and Space Administration

$\mathrm{P}_{1}(\varphi) \quad=$ load in each axial strap

$\mathrm{P}_{2} \quad=$ load in each hoop strap

${ }^{1}$ Aerospace Engineer, Structure Branch, ES2, AIAA Member

${ }^{2}$ Senior Aerospace Engineer, Structure Branch, ES2

${ }^{3}$ Senior Aerospace Engineer, Loads and Structural Dynamics Branch, ES6

${ }^{4}$ Project Engineer, Structural Engineering Division, ES4

${ }_{6}^{5}$ Research Engineer, Structural Mechanics and Concepts Branch, MS 190, AIAA Member

${ }^{6}$ Senior Research Engineer, Structural Mechanics and Concepts Branch, MS 190, Senior AIAA Member

1

American Institute of Aeronautics and Astronautics 


$\begin{array}{ll}\text { Psi } & =\text { pounds per square inch } \\ \text { Psig } & =\text { pounds per square inch, gage } \\ \mathrm{q} & =\text { pressure differential } \\ \mathrm{r}(\varphi) & =\text { distance of a point from the torus axis of rotation } \\ \mathrm{R} & =\text { radius of the cylinder } \\ \sigma_{1} & =\text { axial stress } \\ \sigma_{2} & =\text { hoop stress } \\ \mathrm{t} & =\text { thickness of the shell } \\ \mathrm{TNT} & =\text { trinitrotoluene } \\ \mathrm{TTF} & =\text { time to failure } \\ \mathrm{UTS} & =\text { ultimate tensile strength } \\ \mathrm{W} & =\text { strap width }\end{array}$

\section{Introduction}

Tnflatable structures are a solution to the mass and volume constraints of manned exploration missions beyond low Earth orbit. Bigelow Aerospace has demonstrated the use of inflatable space structures through the launch and utilization of the Genesis I and Genesis II modules launched on a Dnepr rocket in 2006 and 2007, respectively. Bigelow Aerospace will demonstrate a crew-rated space module when the Bigelow Expandable Activity Module (BEAM) is launched on SpaceX-8 and attached to the International Space Station (ISS) Node 3 Aft Port in 2015. Since BEAM's outer diameter is 3 meters (10.5 feet) and it is pressurized to $14.7 \mathrm{psig}$, the stresses will not be as high as if it were a much larger module needed for longer duration space missions.

Creep is a time-dependent failure mode that affects materials under load for long periods of time. Due to the nature of inflatable habitats, the structural restraint materials are at high loads continuously for the entire life of the structure. Creep is therefore one of the most significant factors in assessing the life of an inflatable structure. Due to its high strength and abrasion resistant properties, Vectran (a liquid crystalline polymer) is a prime candidate for use as the structural restraint layer for inflatable structures and was one of the restraint layer candidate materials mentioned in the TransHab patent ${ }^{1}$. Although the manufacturer lists Vectran as having no measurable creep ${ }^{2}$,Vectran has been shown to experience logarithmic creep and stress relaxation ${ }^{3}$ and logarithmic time-dependent failures ${ }^{4}$. When an inflatable module is woven out of webbings, as in the TransHab module, or sewn edge-to-edge as in the Bigelow Aerospace modules ${ }^{6}$, it is hypothesized that there will be an additional reduction in creep life due to the increased number of webbings and potential increased stress encountered due to being loaded and woven or sewn edge-to-edge. For this study, the focus was to understand the creep performance of a woven Vectran inflatable module, and to compare the failure time vs. percent load with individual Vectran webbing testing performed at NASA Langley Research Center ${ }^{4}$. Webbing strain was measured utilizing photogrammetry and the structural dynamic response was measured utilizing accelerometers.

\section{Strap Level Creep Testing}

The restraint layer webbings form the primary structural elements of an inflatable space module, and must sustain a design load for the operational life of the inflatable structure. An extensive test program of individual webbings has been conducted to characterize both the webbing's short-term and long-term behavior ${ }^{4,7}$. The results of these tests inform ongoing design work and support the testing of full-scale modules as discussed and summarized in this section.

Four webbing variants have been studied in two strengths and two materials: $6,000 \mathrm{lbf}$ and 12,500 $\mathrm{lbf}$ rated Kevlar and Vectran. A specific construction (or "architecture") for each webbing strength is defined via the Mil-T87130 specification $^{8}$ and was used for both materials. The webbings and full-scale module are part of a complex structural hierarchy that strongly influences the properties of the final inflatable structure. Unlike metallic structures whose macro-properties are based directly on their molecular properties, softgoods inflatables consist of multiple layers of interacting structural elements, from fibers and yarns to the webbings and final module. Figure 1 illustrates the relationships between the properties and structures at each hierarchical level and the influence of manufacturing, fiber and yarn interactions and weave in both the webbings and inflatable module. This hierarchy leads to higher levels of variance in material behavior and creep life at the webbing level and consequently in the full-scale structure as well. 


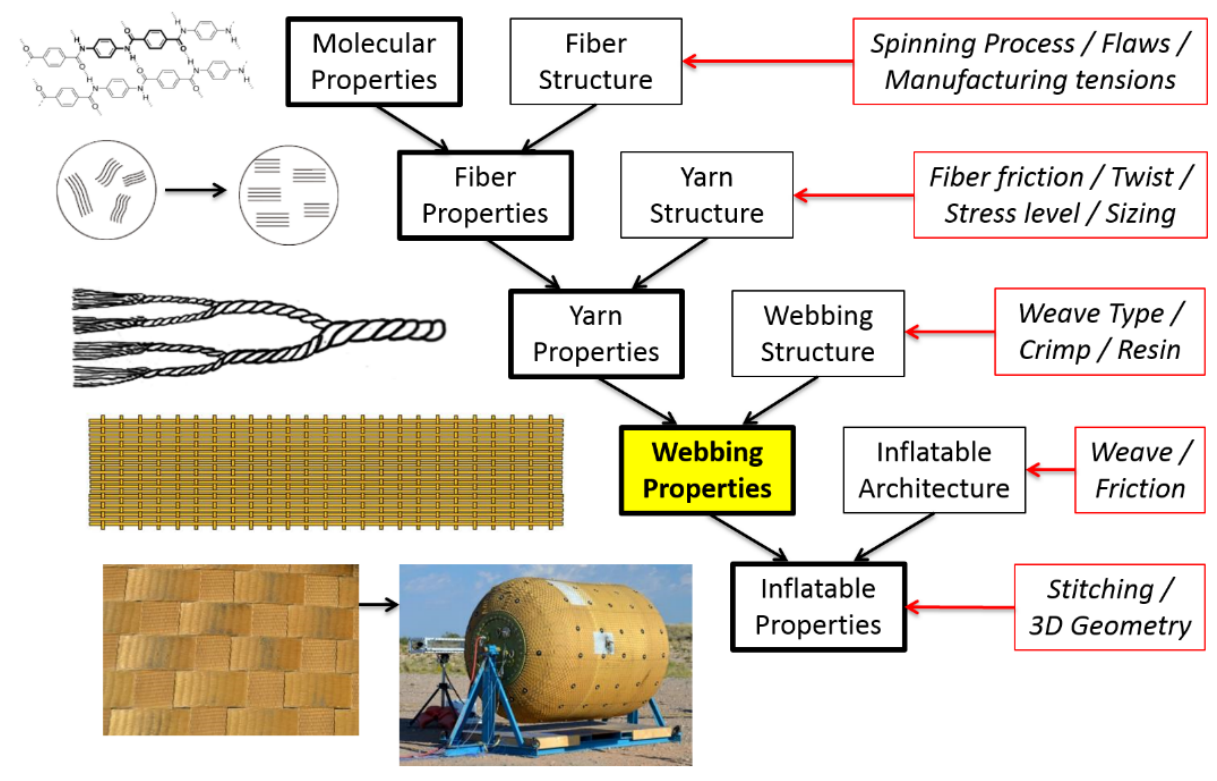

Figure 1. Structural Hierarchy and Characteristics in a Softgoods Inflatable Module

\section{A. Ultimate Tensile Strength Tests and Variance Behavior}

The primary series of short-term tests performed before any creep tests are executed are Ultimate Tensile Strength (UTS) tests. Each of the four webbing variants are manufactured in a run of several thousand yards and are then cut into rolls of material, 25 to 60 yards long. Five UTS tests are performed on each roll to give an average breaking strength. This average UTS can then be used to set the load level for a webbing creep test as a percentage of that average. UTS tests also provide data on strength and stiffness variance across a manufacturing run and provide load vs. strain plots for each roll. Figure 2 plots the minimum, average and maximum UTS for every roll of material tested, along with lines representing the two strength ratings. The Vectran webbings (black) display greater variance in strength than the Kevlar (red) webbings. The Vectran webbings that were rated at 12,500 lbf, exhibit a $9.4 \%$ average total variance about the mean, versus $3.7 \%$ average total variance in the $12,500 \mathrm{lbf}$ Kevlar. Creep life in these materials increases exponentially with a linear decrease in the applied load, thus a large variance in strength can significantly broaden the creep life range. One can also observe the fidelity in which each webbing variant meets the rated load. The Kevlar webbings in both strengths easily exceed the required minimum and do so over a smaller variance in absolute breaking strengths than the Vectran. The 6,000 lbf rated Vectran meets the specification in less than half the rolls (9-of-21), while the 12,500 lbf rated Vectran exceeds the minimum by up to $48 \%$ (18439 lbf), with one roll below the minimum. Both Kevlar and Vectran in the higher strength rating, exceeded the rated load on average by approximately $23 \%$. This indicates the architecture is not well optimized, and Vectran has greater variance (up to twice the range of average UTS values for 12,500 lbf-rated) than Kevlar under the Mil-T-87130 specification. It should be noted that Mil-T-87130 is specified for para-aramids (aromatic polyamides), and although in a similar class of materials, Vectran (an aromatic polyester) is not an aramid. More research is needed on the manufacturing process and specific architectures of these webbings to reduce the variance observed and increase predictability in their strength. Specifically, the tensions, temperatures, yarn paths and coatings used throughout the process would need to be carefully documented and the effects of different weave architectures with the same goal strength would need to be tested and compared to the current webbings to identify optimization approaches. The goal would be a well-documented and repeatable manufacturing approach that could produce several webbing architectures that maintain low variances in both strength and stiffness behavior. 


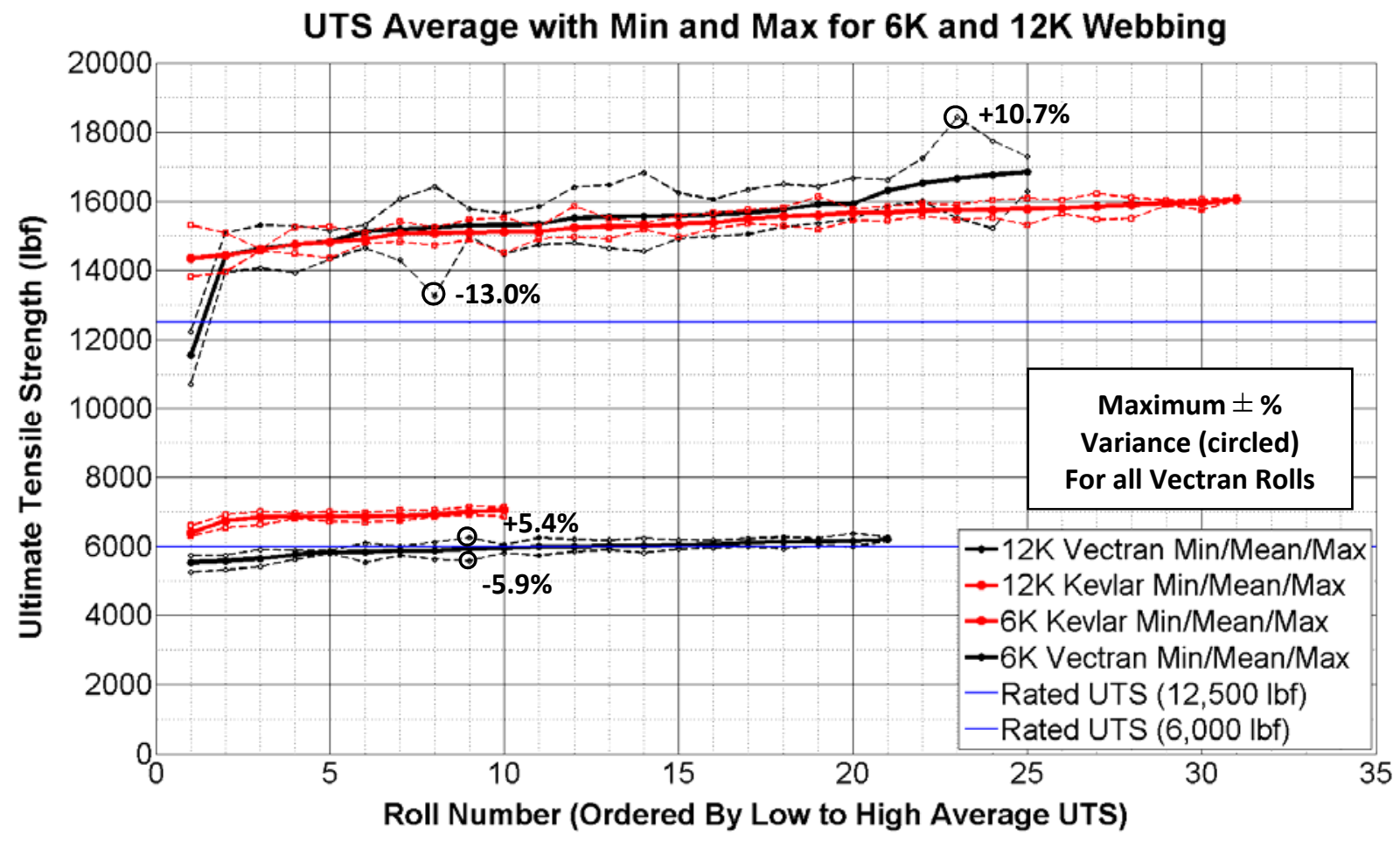

Figure 2. Kevlar and Vectran, 6,000 lbf and 12,500 lbf rated webbings. Minimum, average and maximum UTS points for each roll tested are shown. Solid lines are the average, dashed lines are the $\mathrm{min} / \mathrm{max}$.

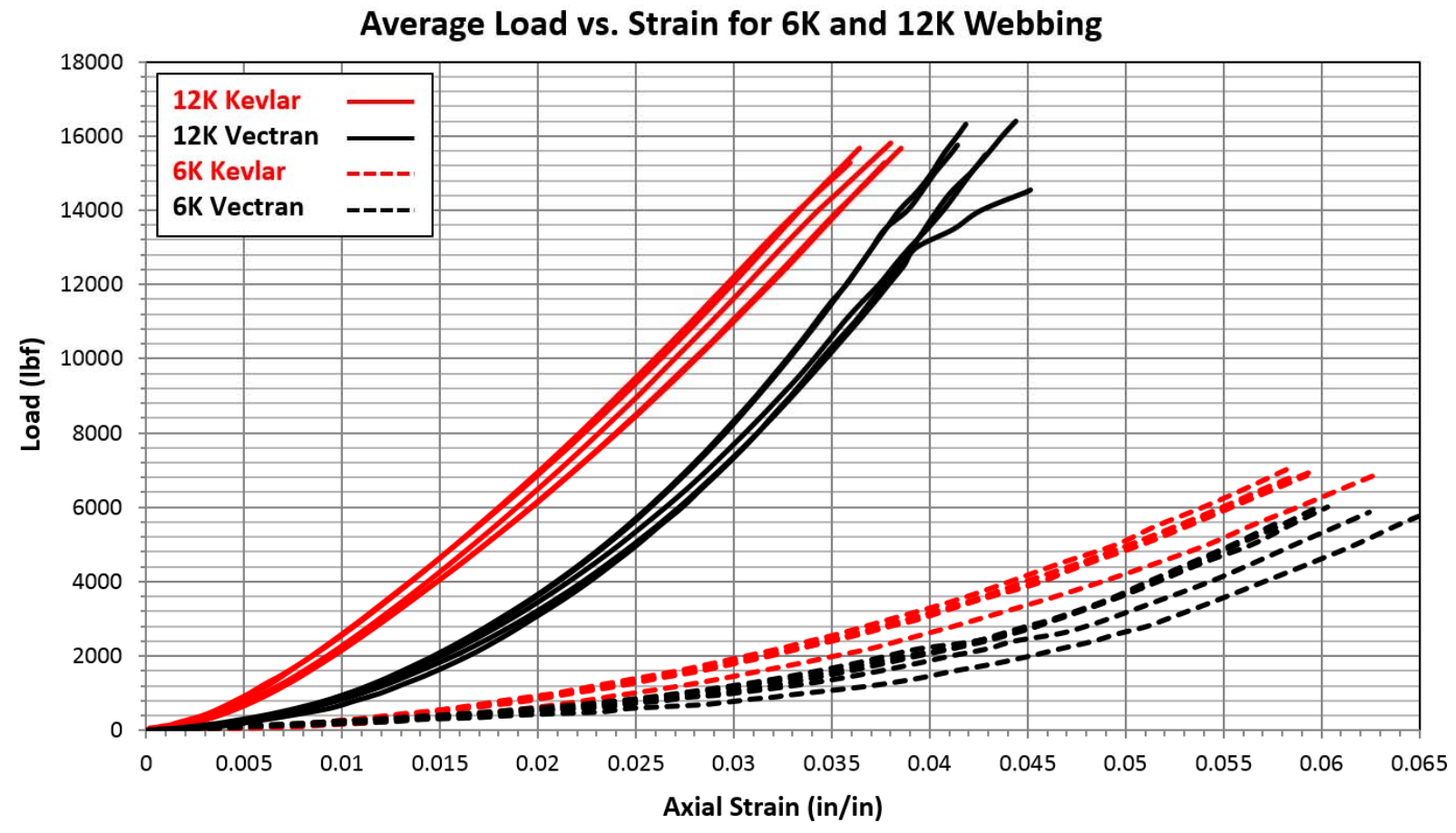

Figure 3. Kevlar and Vectran, 6,000 lbf and 12,500 lbf rated webbings. Average Load vs. Strain curves for five rolls of each webbing variant. Each curve represents the average of five webbings. 
Load versus Strain data from the UTS tests can be used to characterize the stiffness behavior of the webbings and provides a means for converting measured strains into loads during testing of a full-scale module. Once these data are gathered for a given roll or run of webbing, they can be used in coordination with a strain measurement system such as photogrammetry to back-out the loads in the webbings of an inflatable module, as detailed later in this paper. Load is used rather than stress in plots of webbing behavior due to the difficulty in measuring stress precisely from a pliable cross-section. Figure 3 illustrates the variance in stiffness behavior for five rolls of each webbing variant. Given that each roll of a webbing variant is from the same manufacturing run and has the same number of axial fibers (i.e. same architecture), the more compliant curves suggest fewer of those fibers are being loaded and it is likely those rolls would then fail at lower strengths due to higher distributed fiber stresses. This tends to hold true on average for all webbings and is most likely a result of slightly uneven loading of the fibers during load up due to: stick-slip and friction between fibers and yarns, uneven decrimping and fiber-lock, and micro-level differences in the number of flaws. If a better understanding of the mechanisms behind the variance in stiffness behavior can be found, it could elucidate the cause of the high variance in the strength of these webbings. Studying these mechanisms would require instrumentation that could measure small differential movements between fibers and yarns over the length of the test section, and microscopic examination of the fibers for observable flaws over the webbing cross-section. Photogrammetry instrumentation doesn't have the resolution to perform this level of measurement over the full length of the test section, but zooming in and observing only a small area of the webbing precludes the capture of uneven differential movement of the fibers in other areas of the test section. The study of the micro-level behavior of the webbings is therefore currently beyond the scope of this research.

\section{B. Creep Test Results and Time-To-Failure Predictions}

Real-time creep tests of the four webbing variants were performed and detailed in a previous paper ${ }^{4}$, along with descriptions of the three test facilities used in that study. Only the Vectran webbing tests are presented here, as they are the webbings used in the full-scale test module. Figure 4 presents the Times-To-Failure (TTF) of the 6,000 lbf and 12,500 $\mathrm{lbf}$ rated Vectran webbings, loaded to different percentages of the average UTS of the roll they were taken from. A logarithmic curve fit is then calculated through each set of data and two bounding lines (dashed) are plotted that represent the best-fit LOG curve shifted up or down by the maximum $\pm \%$ variance observed from the UTS data (see Figure 2) for that webbing variant. From these curves, an estimate of the creep life range can be predicted given a specified \% UTS load, or a required \% UTS range can be calculated for a desired creep life.

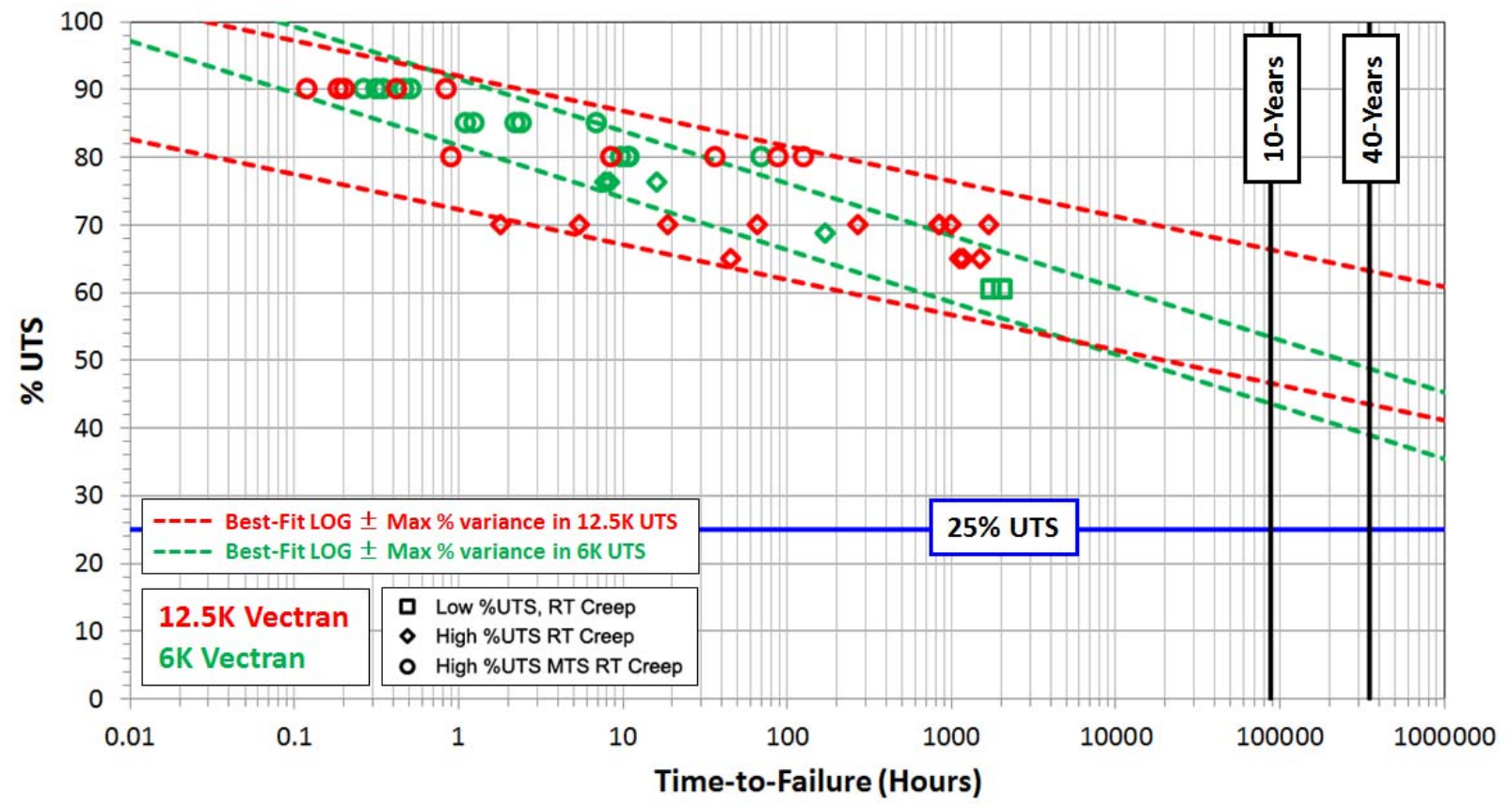

Figure 4. 6,000 lbf and 12,500 lbf rated Vectran. \%UTS vs. Creep Life Time-to-Failure

It can be observed that using the maximum UTS variance as the shift factor for the best-fit creep life curve, bounds the data points extremely well. This illustrates the direct link between the variance in short-term properties and their effects on the long-term behavior of the webbings. It should be noted that if only a few rolls are tested, 
then the confidence in this predicted range is reduced. Consequently, a conservative prediction for the creep life would start with the minimum bound line and add an additional safety factor dependent on the level of variance observed and the confidence in the predicated range due to available test data. Care must also be taken in extrapolating these curves to the right, which assumes all the data at lower loads would fall within the prediction band. The additional effects of aging will begin to impact these polymer webbings if loaded for years to decades, depending on operational conditions (e.g. temperature extremes, atomic oxygen exposure, micrometorid or orbital debris impacts), but it is not currently feasible to run tests for that length of time to assess these factors. Inflatable habitats are typically designed to a safety factor of 4 , thus the operational design loads would be no higher than $25 \%$ of the UTS. The data indicate that even a conservative estimate would put the mission life well beyond 40 years for these Vectran webbings. However, if there is a non-uniform load distribution in the inflatable module, individual webbings may operate at a higher \%UTS. Therefore, to determine a safe mission life for the webbings, a determination of peak sustained webbing loads is required and should be factored in to the use of webbing creep data. Finally, the fact that these webbings are being integrated into a 3D woven geometry, including stitched seams and indexing, which add further variability that must be considered when assessing a safe operating design load for a given mission length.

\section{Module Level Creep Testing}

The objectives of the full-geometry Creep Burst Test performed at the NASA - Lyndon B. Johnson Space Center (JSC) were to:

1) Observe the creep performance of the structural restraint layer, and

2) Verify strap loading at high pressures

\section{Test Article Description}

The test article was fabricated from a weave of one-inch wide Vectran webbing, in the same style developed during NASA's TransHab project. The webbing was manufactured per MIL-T-87130 with the exception that is was fabricated from Vectran. The webbing is woven together in a basket weave pattern ${ }^{1,5}$. Axial straps, running from bulkhead to bulkhead, have a rated strength of $6,000 \mathrm{lb} / \mathrm{in}$. Hoop straps in the cylindrical region of the structure have a rated strength of $12,500 \mathrm{lb} / \mathrm{in}$. The test module is 88 inches in diameter and 10 feet long. There are metal bulkheads on each end with trunnions along the central axis. The module rests on the trunnions in a cradle stand. Interior to the restraint layer is a urethane coated nylon air bladder that is oversized to ensure the restraint layer carries the structural loads and the bladder is not loaded.
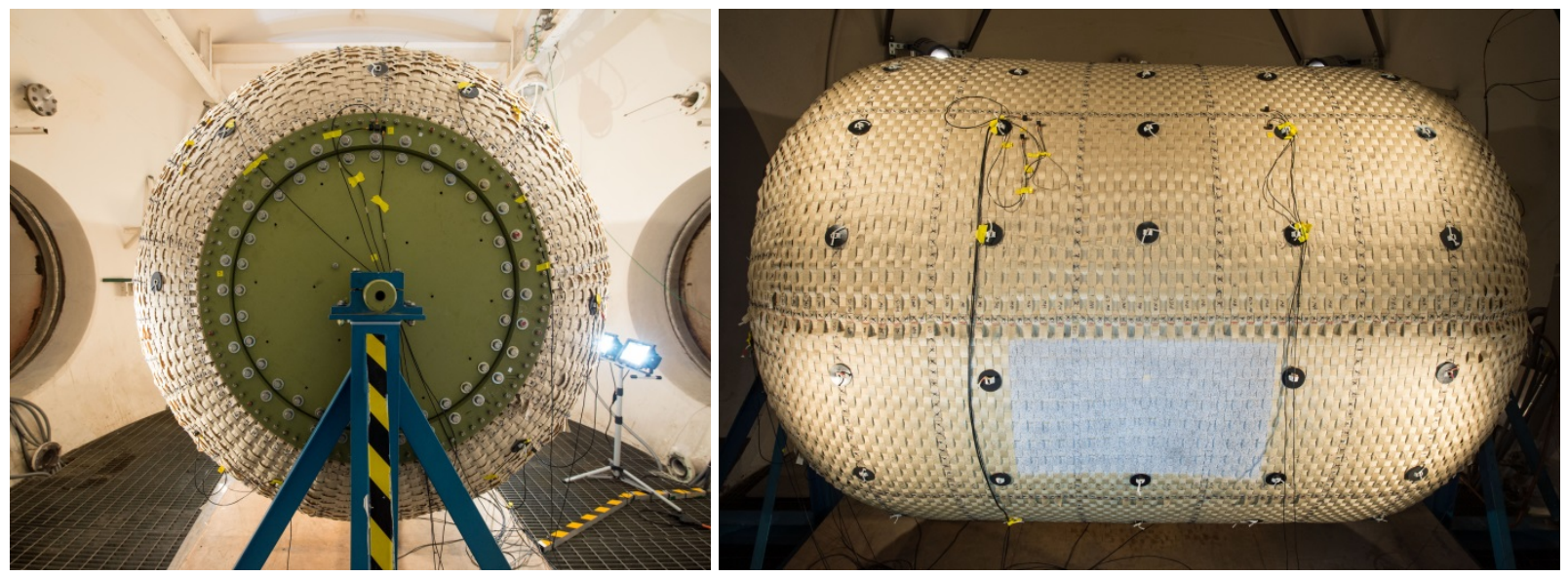

Figure 5. The Creep Burst Test Article. The module is shown inside the test chamber.

\section{Test Setup}

Testing was performed in the Energy Systems Test Area at the NASA-JSC. The test was designed with the understanding that a successful test could be as short as several minutes, or as long as several months. The test article was placed in a 20 -ft. diameter spherical altitude chamber that was originally designed and built for Apollo reaction control systems testing. The chamber's purpose was to safely contain the energy and projectiles released during destructive testing and the environment in the chamber remained at atmospheric temperature and pressure throughout the test. The test article was pressurized with Nitrogen because the facility had existing capabilities for 
high pressure GN2 testing. The pressure control system was designed to be run unmanned after the test article was pressurized and the system was shown to be maintaining a constant pressure. A simple heating and cooling system was installed at the bottom of the chamber to keep the ambient temperature between $40^{\circ} \mathrm{F}$ and $80^{\circ} \mathrm{F}$ in the event of a long test. The test article was instrumented with two pressure transducers to measure the module internal pressure, internal and external thermocouples to measure the internal air temperature and the webbing temperature respectively, and external accelerometers (described in more detail in Section VI).

It was desirable to use high speed cameras to capture video footage of the burst event, but this was not practical due to the possibility of a long test. High speed cameras would have difficulty running continually for such a long period of time, and there was not expected to be any indication that a burst was imminent in the moments before a burst occurred. Also, for safety reasons, personnel were not allowed in the test chamber, or the test cell surrounding the chamber, after the test article pressure surpassed 5 psig. The test setup had to be configured such that no modifications were required in the test cell if the test continued for several months. For these reasons, it was decided to record video footage on three cameras at 60 FPS. Two cameras were inside the chamber in the "ears" on the east and west sides of the chamber, 180 degrees apart. The third camera was outside the chamber on the top, looking through a viewing window. The east ear also contained a pair of additional cameras to record still images for photogrammetry. Photogrammetry is described in detail in Section V. Protective enclosures were built for all of the cameras inside the test chamber. Lighting was provided by eight LED lamps mounted to the walls of the chamber.
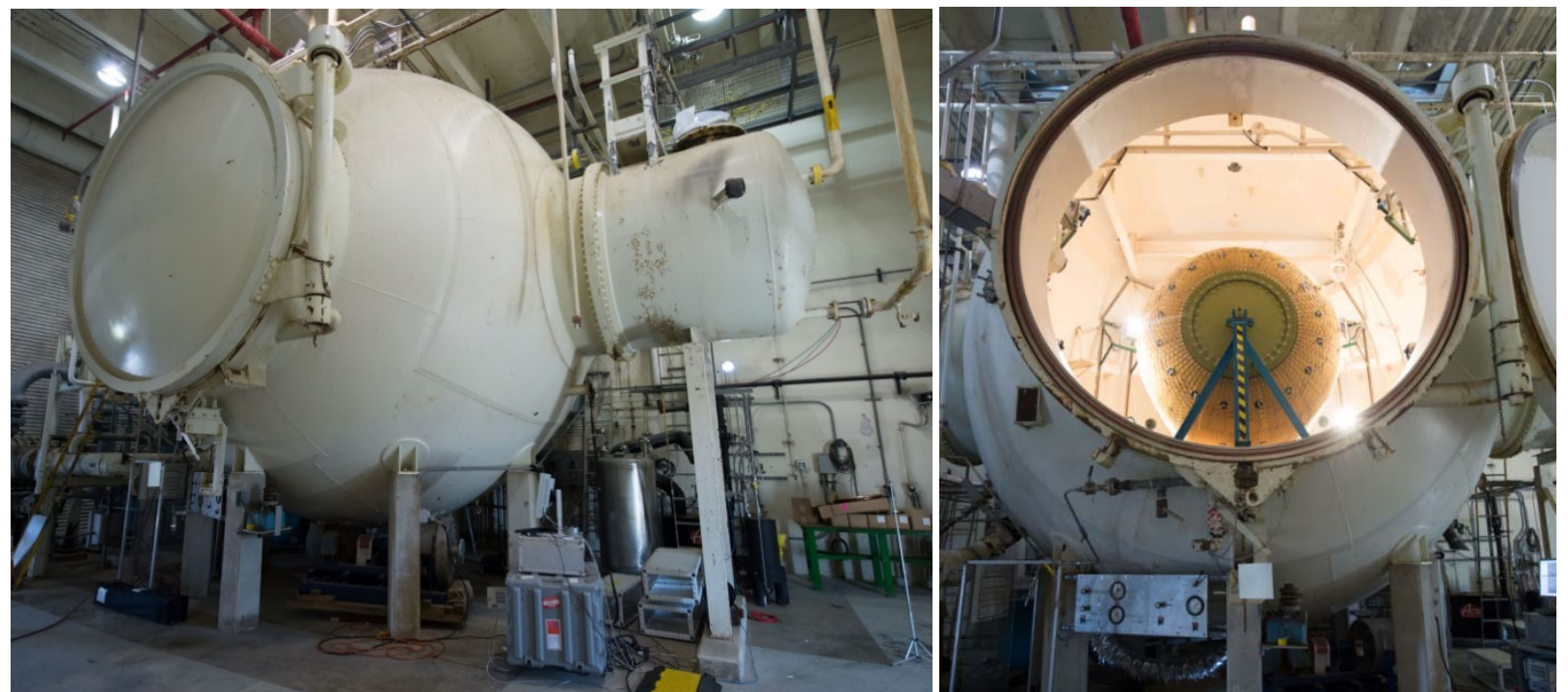

Figure 6. The test chamber at the JSC Energy Systems Test Area where the Creep Burst Test was performed.

\section{E. Test Predictions}

The load predictions for the webbing straps are based on membrane stress equations for cylindrical and toroidal pressure vessels. This process was developed and refined at NASA-JSC during the TransHab project. The analysis is capable of including factors such as strap spacing or overlap, seam efficiency, and the non-uniform loading of hoop straps in the toroidal section for the purposes of designing module restraint layers. The test article used for this test was designed as a cylinder with toroidal end caps at a design pressure of $36 \mathrm{psig}$. The module is a $1 / 3$ scale representation of a flight concept that would operate at $12 \mathrm{psig}$, so in order to achieve the same load on the $1 / 3$ scale representation, the operational pressure must be multiplied by a factor of three. Since the test was conducted at pressures far exceeding the module design pressure of $36 \mathrm{psig}$, this approach may not accurately represent the loads in the structure since the test article's internal pressure, and therefore the geometry, deviate from design conditions. 


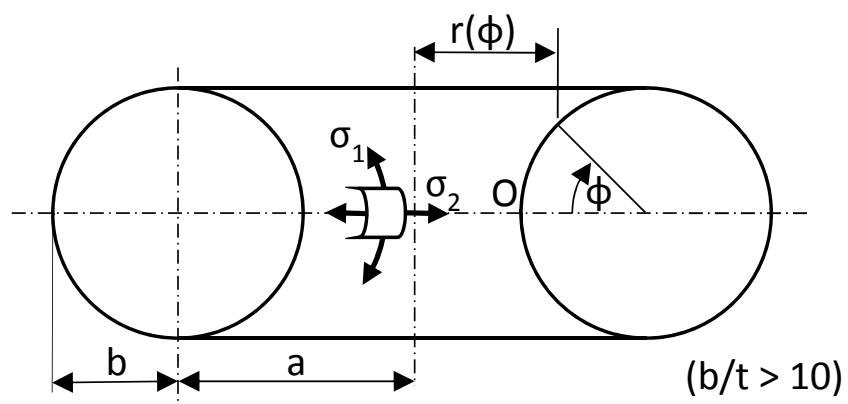

Figure 7. Toroid shape diagram.

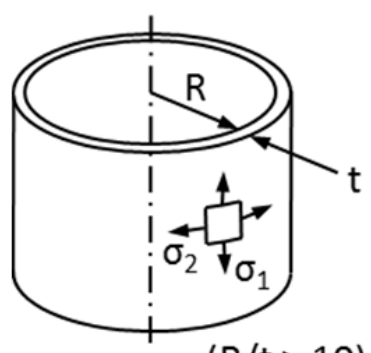

$(\mathrm{R} / \mathrm{t}>10)$

Figure 8. Cylinder diagram.

The equation for the axial stress in a cylindrical pressure vessel is

$$
\sigma_{1}=\frac{q R}{2 t}
$$

where $\mathrm{t}$ is the thickness of the shell and $\mathrm{q}$ is the pressure differential between the inside and outside. The equation for hoop stress in a cylindrical pressure vessel is

$$
\sigma_{2}=\frac{q R}{t}
$$

The equation for the axial stress in a toroidal pressure vessel is

$$
\sigma_{1}(\varphi)=\frac{q b}{2 t} \frac{r(\varphi)+a}{r(\varphi)}
$$

where $r$ is a function of $\varphi$ measured from point $\mathrm{O}$. The equation for the hoop stress in a toroidal pressure vessel is

$$
\sigma_{2}=\frac{q b}{2 t}
$$

The thickness of the shell wall is not typically included in the analysis of fabric structures, so the results of Equations 1-4 can be reported in units of load per unit length. The equation for the load in each axial strap is

$$
P_{1}(\varphi)=\sigma_{1}(\varphi) \frac{2 \pi r(\varphi)}{n_{1} w}
$$

where $n_{1}$ is the number of axial straps and $w$ is the width of the straps. The equation for the load in each hoop strap is 


$$
P_{2}=\sigma_{2} \frac{L_{1}}{n_{2} w}
$$

where $L_{1}$ is the length of the axial strap and $n_{2}$ is the number of hoop straps.

In the design of the test, it was decided that it was preferable to error on the side of bursting the test article early in the test, than to risk the test running beyond the timeframe planned. The test article would need to remain at pressure for a period of time before bursting in order for the burst to be considered a creep failure. Previously, two Vectran modules of this same design were burst hydrostatically at a pressure of $196 \mathrm{psig}$. It is assumed that a static pneumatic burst would occur at approximately the same pressure. This assumption, and the results of the strap level creep testing were used as a rough prediction of the time to failure for planning purposes. In both of the hydrostatic burst tests, the failure initiated with the breakage of several axial straps. The axial straps have a rated strength of $6,000 \mathrm{lb} / \mathrm{in}$, and have a lower margin than the $12,500 \mathrm{lb} /$ in hoop straps. The strap level creep tests of $6,000 \mathrm{lb} / \mathrm{in}$ Vectran webbing suggests that a single strap loaded to $74 \%$ of its breaking strength would break in a time ranging from several hours to several days. This range of test time was desirable because even if the module-level creep performance was different from the strap-level creep performance, the time-to-burst was still likely to fall within the limits of the planned timeframe. A test pressure of $74 \%$ of $196 \mathrm{psig}, 145 \mathrm{psig}$, was selected. At this pressure, the TNT equivalent for the test article volume is $7.44 \mathrm{lbs}$. The burst of an inflatable is not expected to resemble an explosion of TNT, but the TNT equivalent was used as a conservative prediction for planning and safety preparations.

The failure of the test article was not necessarily expected to resemble the hydrostatic burst failure. The hydrostatic burst test failure occurred within a fraction of a second. Damage tolerance testing has shown that the restraint layer can withstand the breakage of a single axial strap at operational pressure without catastrophic failure? and further testing has shown the restraint layer can also withstand the breakage of two side-by-side axial straps and two side-by-side hoop straps at the same location (simulating a micrometeoroid strike) at pressures exceeding operational pressure without catastrophic failure. It was possible that a creep failure would have occurred over a longer period of time as individual straps failed at various points in time, until the air bladder became unsupported and sprang a leak.

\section{Test Observations}

The test was performed on March 11, 2014. The module was first inflated to a pressure of 0.5 psig for the installation of instrumentation, calibration of photogrammetry cameras, and inspection of the restraint later straps. The test article was inflated to a proof pressure of $5 \mathrm{psig}$, held at pressure for several minutes, and then vented down to $2.5 \mathrm{psig}$. At $2.5 \mathrm{psig}$, personnel were allowed to approach the test article for one final verification check before the chamber was sealed and the pressure was increased. Over a period of more than 3 hours, the test article pressure was increased from $2.5 \mathrm{psig}$ to the target pressure of $145 \mathrm{psig}$. There were several arbitrarily selected hold points

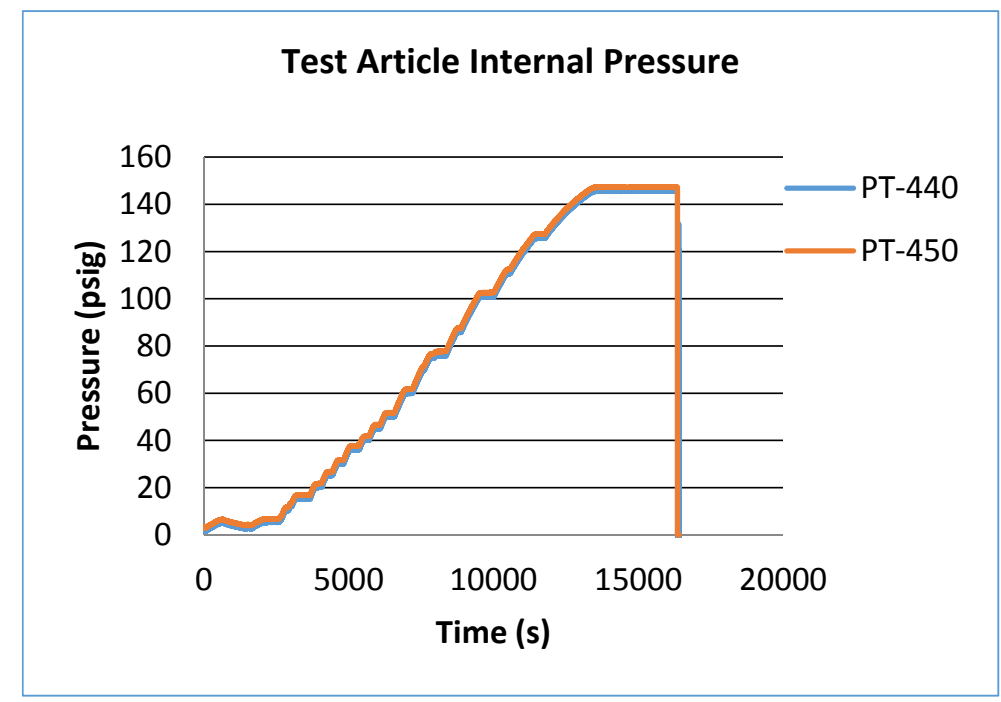

Figure 9. Test Article Internal Pressure vs. Time.

y

American Institute of Aeronautics and Astronautics 
during the pressurization for the purposes of collecting accelerometer data. At each hold point, the pressure was held constant for several minutes. These holds occurred at 5, 15, 36, 50, 75, 100, and $125 \mathrm{psig}$. Upon reaching the target pressure of $145 \mathrm{psig}$, the pressure was held constant. Actual pressure readings on the two test article internal pressure gages were 145.55 psi and 147 psi. During the pressurization, sounds could be heard that can best be described as "pops". These sounds have been heard in other pressurization tests of woven inflatable test articles. The pops are believed to be the straps overcoming static friction and sliding relative to each other. These events were picked up by the accelerometers and are discussed in more detail in Section VI.

After 49 minutes holding at the test pressure, the test article experienced a dramatic burst event. The event occurred in a fraction of a second, and produced an explosion loud enough to shake the building. Immediately before the burst event, personnel monitoring the test from the control room did not observe any signs indicating that a failure was imminent. The final frames of the test video are shown in Figure 10, Figure 11, and Figure 12.

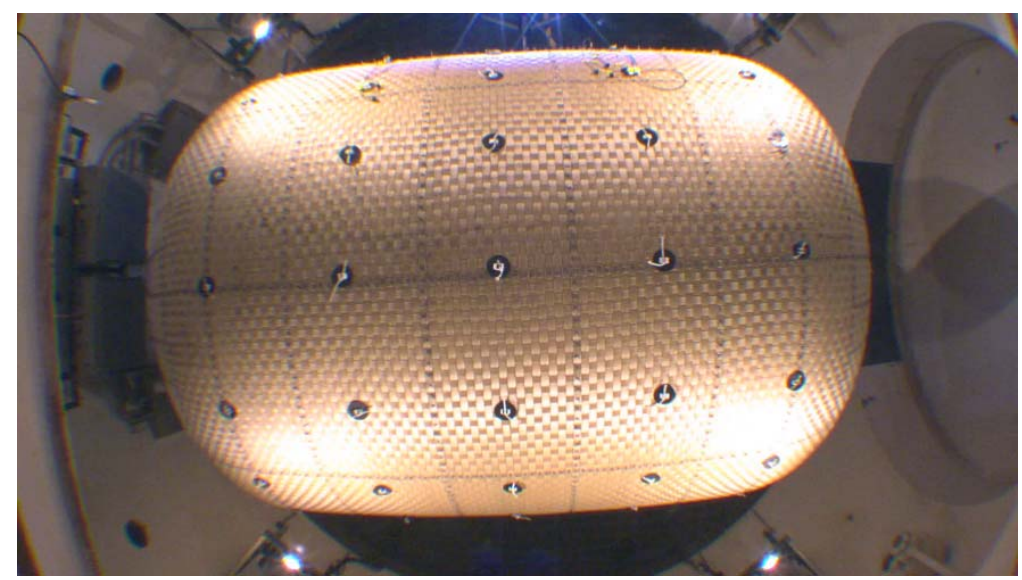

Figure 10. Video of burst - Frame 1.

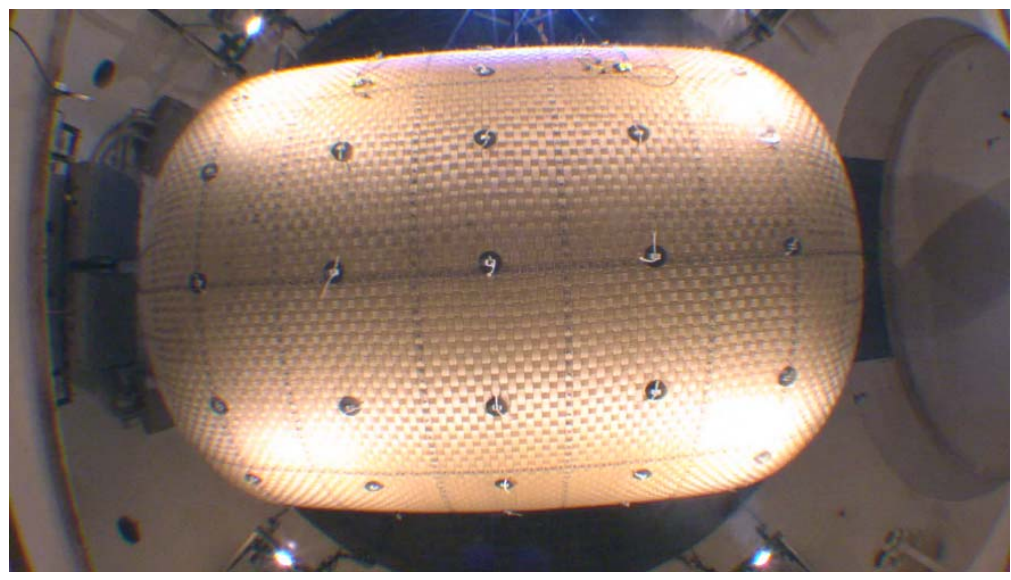

Figure 11. Video of burst - Frame 2. 


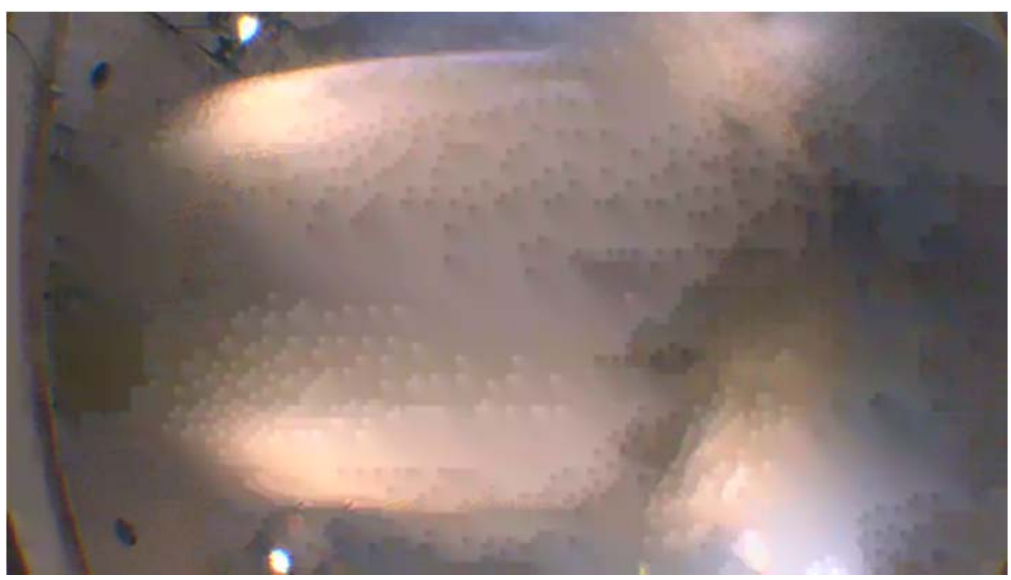

Figure 12. Video of burst - Frame 3.

The post-test failure investigation included mapping the locations where the straps broke. All of the axial straps broke, and none of the hoop straps broke. The break points varied from strap-to-strap, but were concentrated toward the right bulkhead (when viewed as shown in Figure 10, Figure 11, and Figure 12). The broken ends of the straps were frayed more than is typically seen in individual straps tested to failure, which is likely related to the dynamics associated with a pneumatic burst event. The location of failure initiation could not be conclusively identified without high speed video, but from what could be seen in the test video and in post-test examination of the test article, the burst event appeared similar to previous hydrostatic burst events conducted with this style of restraint layer.

\section{Photogrammetry}

The Aramis system, a non-contact three dimensional digital image correlation system, was used to capture the strain data from the straps. The system consists of a pair of 1.3 megapixels cameras, a camera controller, and a computer that runs the software. The camera pair is calibrated for a specific volume, and the system recognizes the area by means of contrasting pattern on the surface of the test specimen.

An area of the test article was prepared and painted with a flat white background and a flat black speckled pattern in the foreground. This allows for the Aramis system to distinguish and correlate the images from the left camera with the images from the right camera. With homogeneous materials, the process is relatively simple. With weave-like patterns (see Figure 9) where the straps are moving and tensioning in different directions, the process is more involved.

To avoid interaction between adjacent straps,

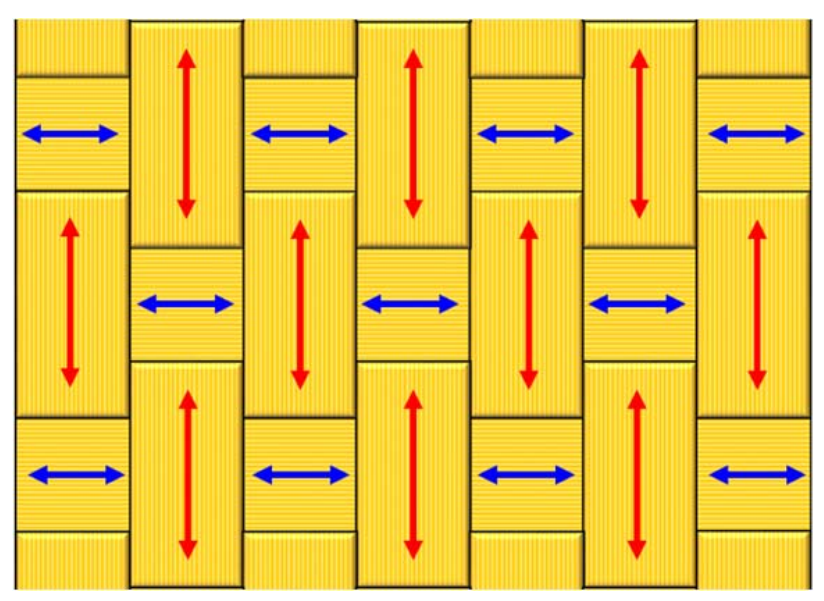

Figure 13. Weave pattern and the strain direction for each of the straps.

masking around the chosen straps is necessary (see Figure 10). Once the mask is created, the individual areas can now be correlated and processed into 50 sections for the Hoop straps and 28 sections for the Axial straps. The results are two different sets of measurements, one for each axis the strap is tensioning. As an outcome, we receive a better result in the data where the strain is not being influenced by the movement of adjacent straps. 


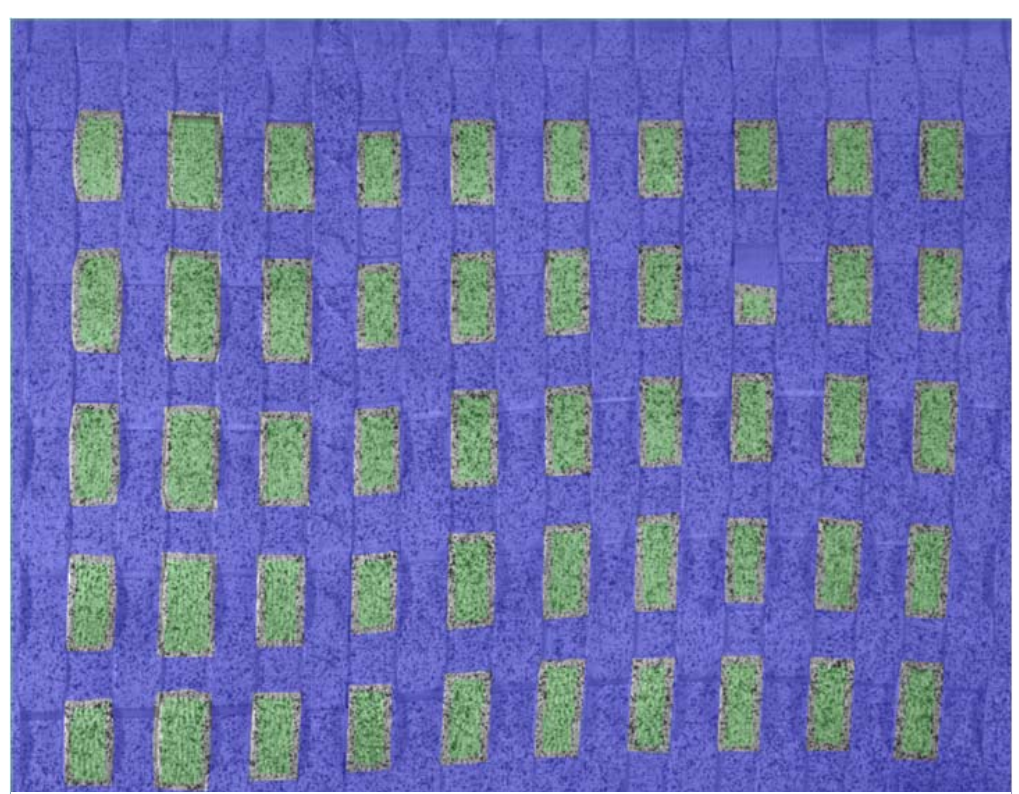

Figure 14. Masking technique to isolate the Hoop straps prior to processing.
Another issue when working with the weave structure is shadows. When processing for strain, a reference image is taken when the loads are at their lowest and the module can still hold its shape. Because there is little to no tension in the straps, some of the slack straps are raised and are casting shadows. This is usually mitigated somewhat by the use of lights in key locations to compensate. As a result, some areas of the straps are not correlated entirely.

Since we are dealing with relatively small areas for each orientation (Axial and Hoop), it was necessary to increase the number of points to calculate deformations. Several techniques to process the image at a higher resolution were needed for the analysis system to handle the load of the increased number of data points. Aramis uses various square correlation areas, known as facets, as measurement points to observe the deformation of the test specimen ${ }^{10}$. To increase the amount of data points, a higher overlap between facets is crucial. This is call a "Facet Step". As an example (Figure 11) a square facet size of 15 pixels and step size of 4 pixels will have an overlap of $73 \%$ while one with a step size of 11 pixels will have an overlap of $27 \%$. Therefore the 15 pixel by 4 pixel parameters will create a denser population of data points for each section of strap.

Next is defining the start point, which is a selected facet that can be correlated between the left and right camera for each recorded image. In a homogeneous material, only one start point is necessary. In a weave structure with areas that are separated by the masking process, a start point is set for each individual area. Once defined and computed, the data can be evaluated.

During the analysis, an average of the data points in each section of the strap was computed. The statistical analysis tool within the Aramis software is used to calculate the average strain for each section of each strap for a specific strain axis. The results can be plotted (see Figure 16) within the Aramis software or exported for further analysis with other tools. The data acquired through photogrammetry will be discussed in Section VII.
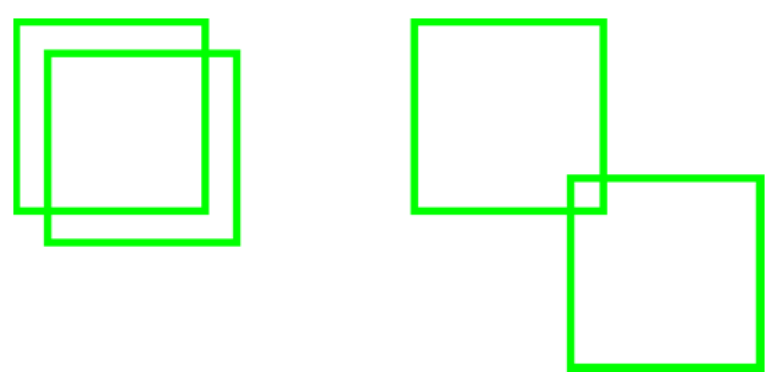

Figure 15. Showing the difference between facet steps for a given size facet. Large overlap (left), and small overlap (right). 

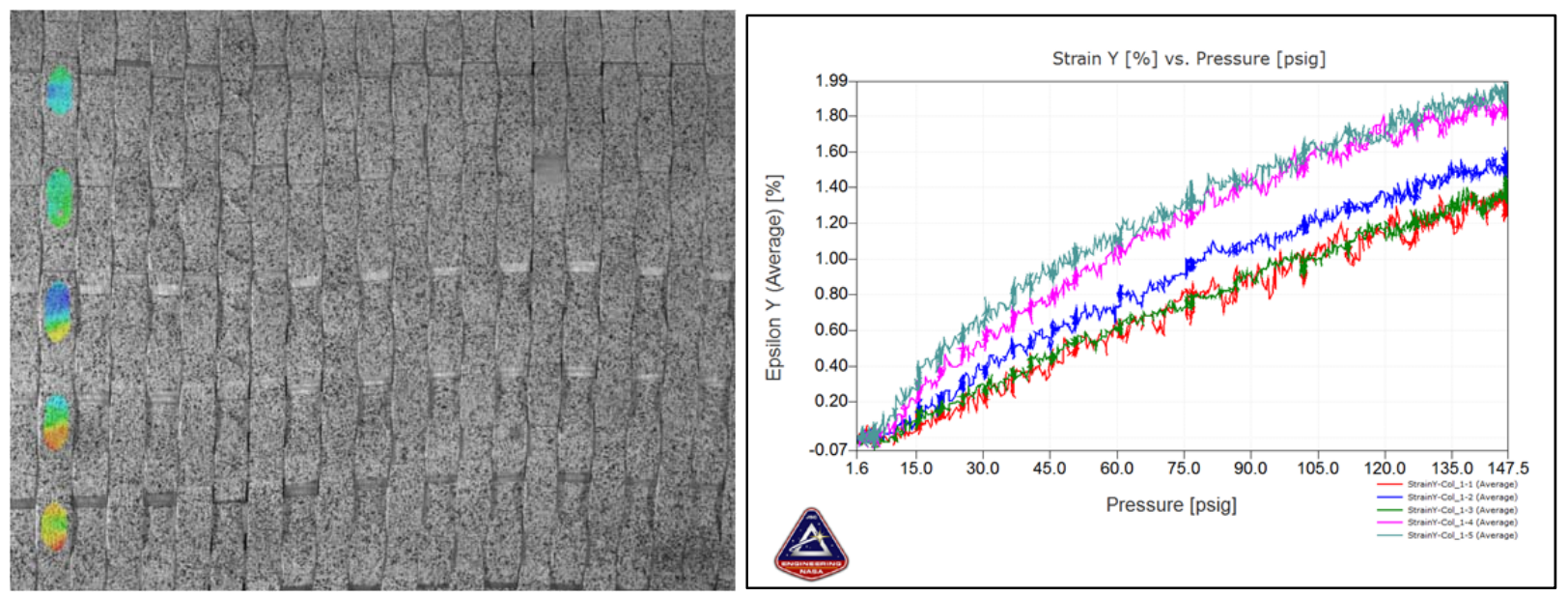

Figure 16. Hoop strain in the $Y$ axis with data overlay and its respective plot.

\section{Structural Dynamics}

The structural dynamics response of any structure (even an inflatable one) represents measureable metrics that may be interpreted for understanding of structural health, environmental loading, induced loads, test margins, or analytical fidelity. These responses show up on a continuum of global response (generally low frequencies) to highly localized responses (generally higher frequencies). Accelerometers are the most common and versatile sensors for structural dynamics measurements. Typical structural dynamics measurements are processed with a known measurement of the forces being imposed on the structure. Operational analysis techniques are used when no distinct measurement of the input force is available ${ }^{11}$. This section provides the introductory details and quick-look data from the accelerometer complement of the Creep Burst Test. Additional details from the on-going effort to analyze and understand the structural dynamic information is included in the companion paper ${ }^{12}$.

Fifteen Kistler 8632C10 PiezoBEAM cube accelerometers were mounted on the test article while inflated at 2 Psi delta pressure. These piezoelectric sensors were rated to measure $10 \mathrm{~g}$ of acceleration in either direction and were configured as a cube with a .56-in x .56-in x .56-in footprint. Previously, these sensors were used for structural health monitoring measurements on the Space Shuttle Orbiters as part of the Shuttle Modal Inspection System $(\mathrm{SMIS})^{13}$. The sensors were not expected to survive the failure of the test article. Figure 5 shows global context images of the sensors and the associated cabling installed on the test article. Figure 17 shows close-up images of sensors installed on the soft goods and metallic core of the test article. Figure 18 and Figure 19 show schematics of the test article with the accelerometer locations and directions denoted. 


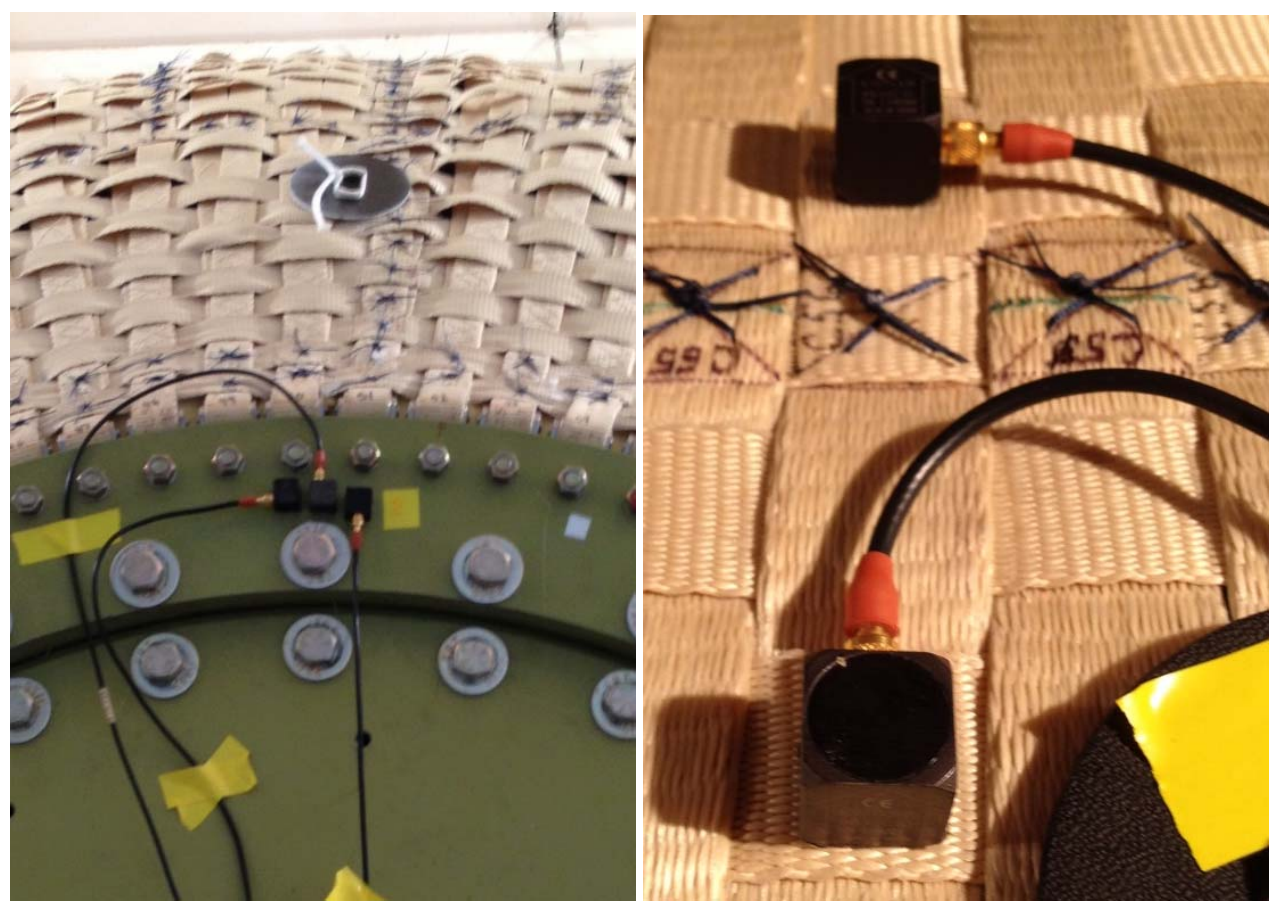

Figure 17. Close-up Images of Installed Accelerometers on the Creep Burst Test Article

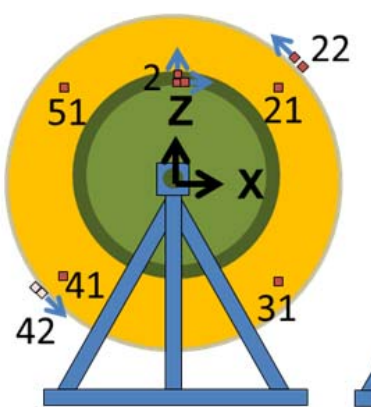

Side View

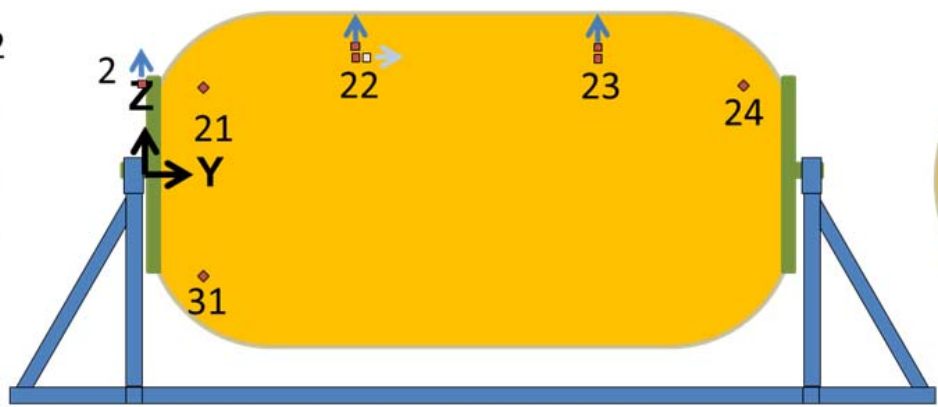

Front View

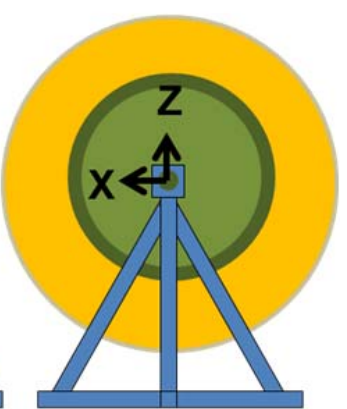

Side View

Figure 18. Location and Direction Schematic of Installed Accelerometers (Three Views)

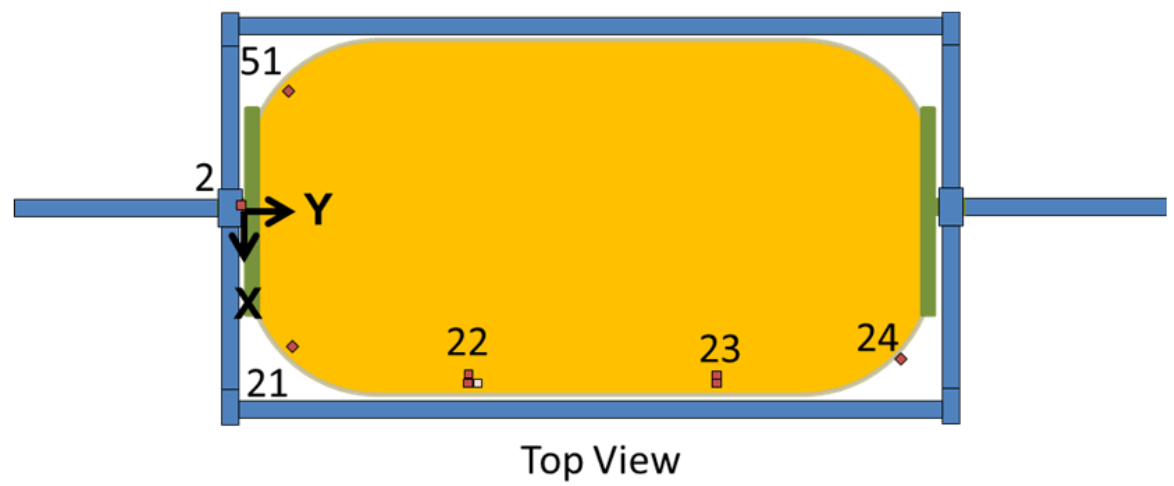

Figure 19. Location and Direction Schematic of Installed Accelerometers (Top View) 
An important consideration in preparing for the test was how to attach the accelerometers to the soft-goods of the test article. The sensors would need to be installed at the low test article pressure of 2 psig, yet need to function up to and including the final test article pressure of $146 \mathrm{psig}$. It was anticipated that the straps of the restraint layer would expand and move during the ramp up to the test pressure. Also, the mounting technique had to be robust to function for several weeks or months as well as provide no-impact to the performance of the test. Another consideration was that it was expected to be difficult to provide any resistance force to the sensor during mounting except for the 2 psig internal pressure of the test article.

A test using a single strap of the restraint layer material loaded in a tensile test machine was used to assess installation techniques. Two different adhesive tapes (which had previously been tested for other long-term sensor installation applications) were assessed. Each adhesive was assessed using an installation with and without back pressure being applied during installation. The single strap was loaded with the equivalent force that a similar strap would see on the test article with an internal pressure of $2 \mathrm{psig}$. Four sensors were installed in each of these test case combinations and then the tension was increased to the equivalent of the $146 \mathrm{psig}$ test pressure. Both adhesive systems performed well during the test both with and without back pressure. However, the 3M F9473PC adhesive tape appeared to be a more tenacious application with no back pressure and was selected for use to mount the accelerometers in the test.
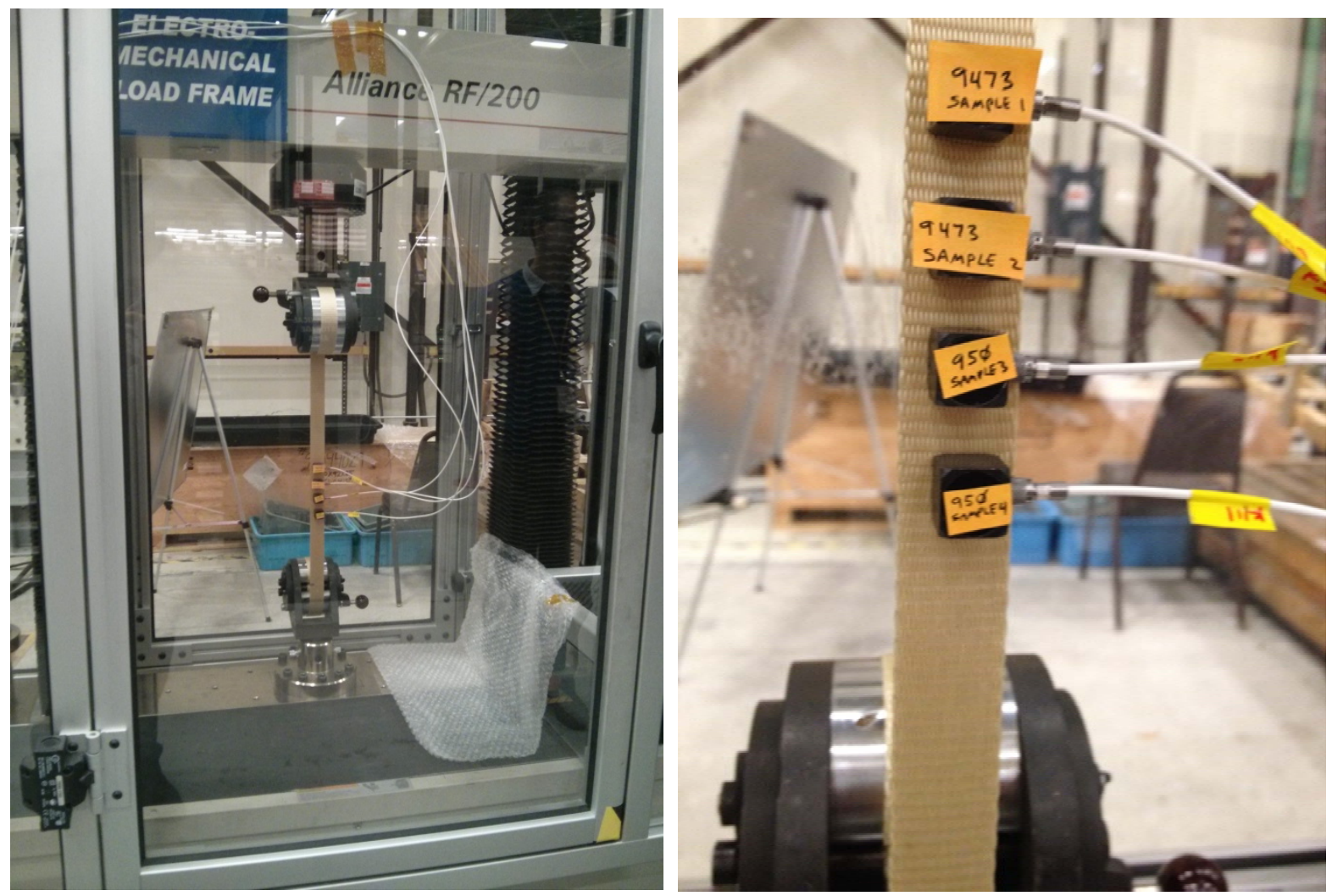

Figure 20. The Single Strap Test to Assess Adhesive Accelerometer Mounting Systems

Twelve of the 15 applied sensors were monitored during the test using a Bruel and Kjaer LAN-XI Type 3053-B120 portable data acquisition module driven by the B\&K Pulse software. Using Figure 18 and Figure 19 as a reference, the two sensors at location 42 and the $\mathrm{Y}$ direction sensor at location 22 were not monitored. These sensors were to be treated as spares/supplements for use during the test, which could have lasted several weeks. Microdot to BNC cables of 120 -foot length were used to connect the sensors to the 3053 module, which was in a shielded control room adjacent to the chambered test article. It should be noted that these sensors, the 3053 module, and the Pulse software were used to perform a traditional hammer-based modal test on the test article prior to installation in the chamber as well as during the single strap test mentioned above.

The data acquisition was set up to take data in contiguous five minute blocks of data, which were sampled at 4096 samples per second. Anti-aliasing filtering was used and the resulting data have been assumed useful up to $1300 \mathrm{~Hz}$. A nearly continuous five-hour data stream from test start until failure was recorded. The test article was 
pressurized from .5 psig until 146 psig with specific holds at $5,15,36,50,75,100$, and 125 psig to allow fiveminute increments of steady state accelerometer data before reaching the final test pressure of 146 psig. Figure 21 provides both a full five-minute data sample, and the first one-second data sample, at location 21 (refer to Figure 18 and Figure 19) during the low-pressure 5 psig hold. The data appear as would be expected with an identifiable vibration signature. Figure 22 also provides both a five-minute, and first one-second data sample of the sensor at location 21, but at the final test pressure of 146 psig. Note that the dominant features are now randomly-spaced, impulse excitation events. These events not only visibly dominate the plots but also can significantly raise the vibration floor of the data when they occur.

These impulse events, as seen in Figure 22, make a traditional modal analysis of these data challenging. However, techniques to effectively process the data have been developed and are reported in the companion paper ${ }^{12}$. One feature that has been extracted from the vibration noise floor is a fairly consistent $1000 \mathrm{~Hz}$ dynamic phenomenona. This feature can be found in the data throughout the entire test. The interesting aspect of this feature is that it does vary throughout the test (including the run-up to failure). Figure 23 shows the quick-look estimation of the frequency of this phenomenona during several of the constant pressure data sets. The frequency increase from around $1000 \mathrm{~Hz}$ to approximately $1013 \mathrm{~Hz}$ suggests that this phenomenona is a feature of the test article and does not have an external or electrical source. The low damping and consistent presence suggest that there might be any number of sources including a leak or an acoustic phenomenona. However, a lightly damped and easily excited mode of the test stand/metallic core is also a possibility. Efforts continue to understand this phenomena and to more fully characterize the other phenomenona in the data. As a note, there are a rich set of dynamics phenomena in the 100 to $400 \mathrm{~Hz}$ region in certain directions as well as some electrical harmonics that appear in the data.
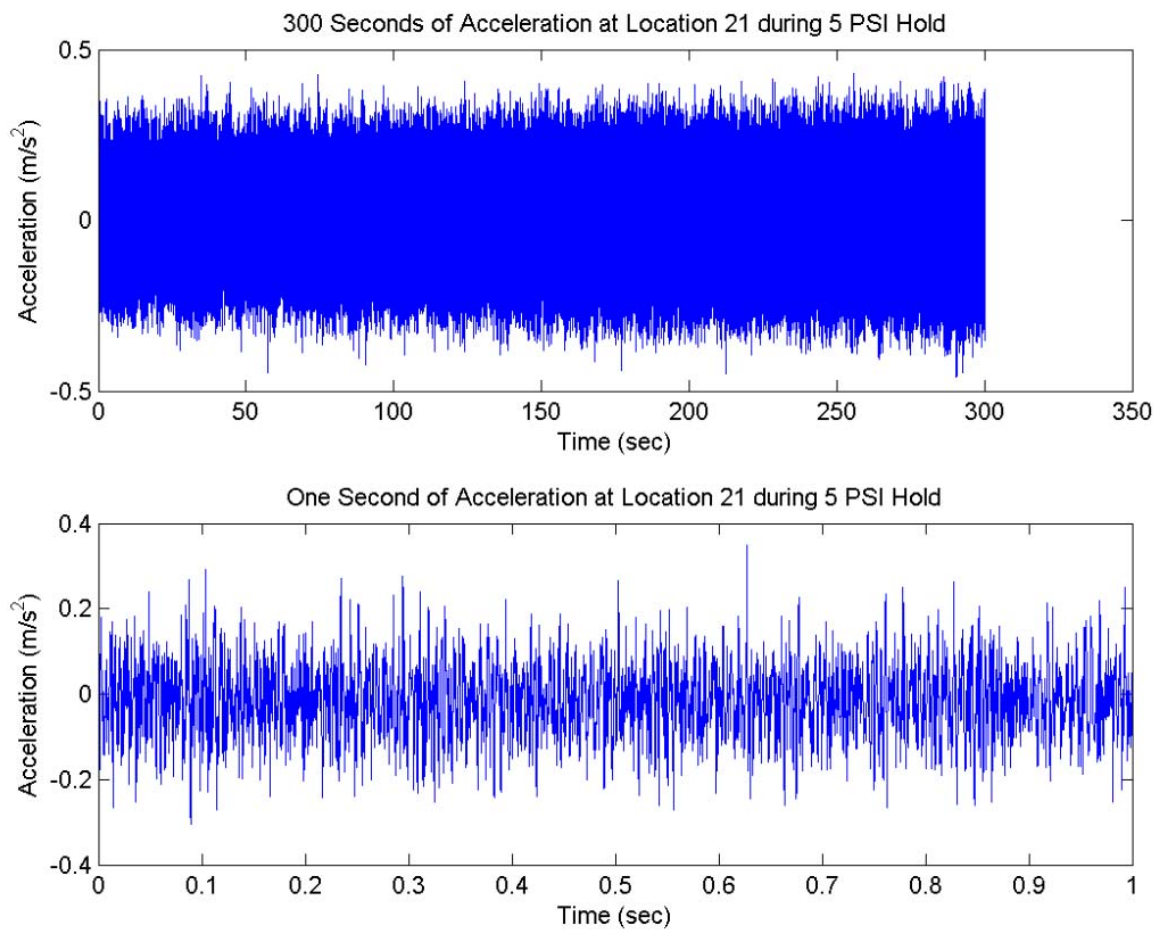

Figure 21. Five Minute and One second Accelerometer Time History at 5 PSI Hold 

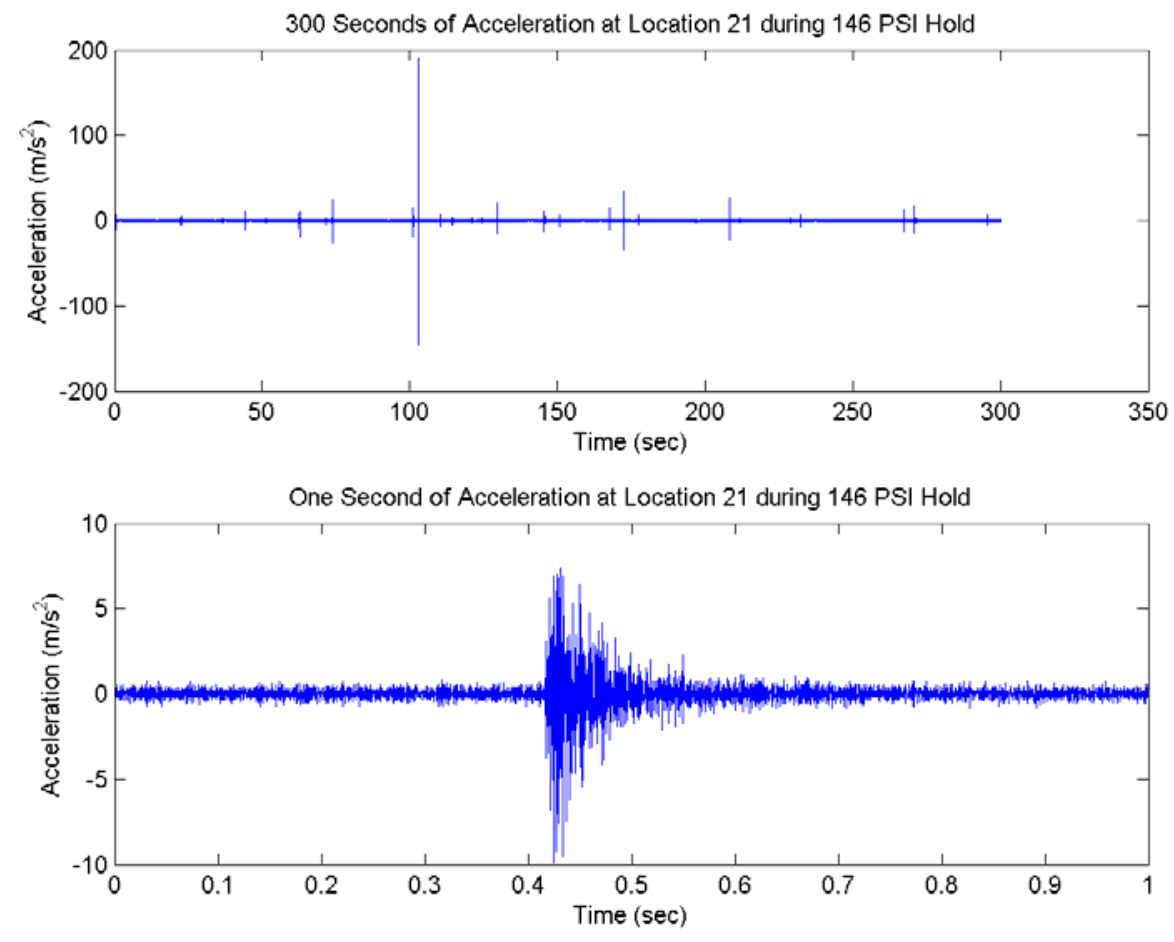

Figure 22. Five Minute and One second Accelerometer Time History at 146 PSI Hold

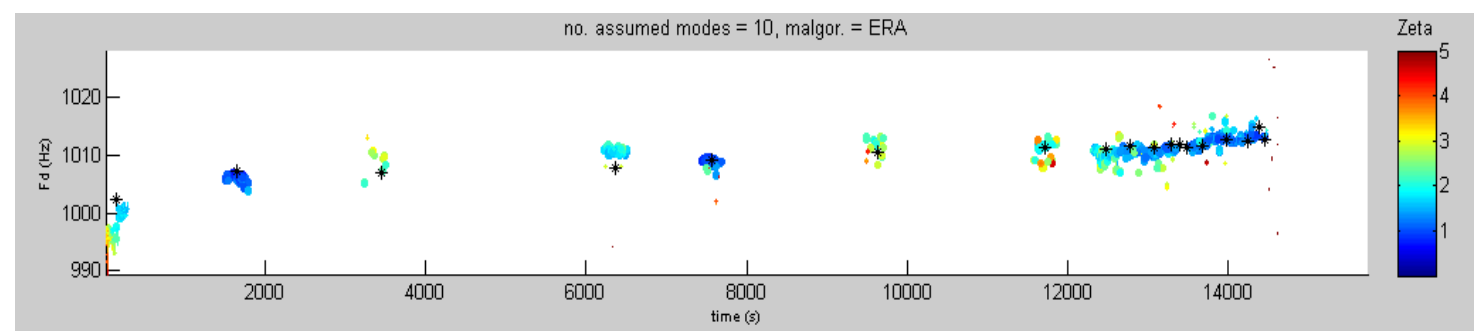

Figure 23. Trend of Increasing Frequency of the $1000 \mathrm{~Hz}$ Phenomena with Time

Additional analysis efforts that are underway or planned include: (1) additional studies of the impulse events as stand-alone metrics, (2) trends seen in other dynamics phenomena besides $1000 \mathrm{~Hz}$, (3) data analyzed from regions unaffected by the impulse, (4) modelling results using low-pressure modal tests as correlation, (5) further assessments of the single strap test data to correlate pressure effects, (6) inclusion of the microphone, pressure, and photogrammetry data to look for emergent trends in the accelerometer data, (7) the estimation and use of Ritz vectors $^{14}$, and (8) inclusion of force reconstruction techniques ${ }^{15}$. The Ritz vector work offers the possibility of obtaining some estimate of the location and response to the impulse events. The force reconstruction techniques also provide the capability to directly use the structural response to the impulse events. Advanced techniques that the team is developing include an integrated approach using a correlated model, Ritz vector estimation, and force reconstruction to obtain understanding of the source of the excitation events.

The overall goals of the accelerometer analysis efforts have been to support the inflatable structures project team as it works to understand the creep burst test results, to develop techniques that can be used to monitor the health and condition of inflatable structures, and to gain experience in using operational analysis tools that can be applied to inflatable modules on-orbit. 


\section{Strain Data Results}

Strain data were obtained from the photogrammetry images, as described in Section V. Five Axial straps (shown horizontally in Figure 24) and ten Hoop straps (shown vertically in Figure 24) were selected for the first round of analysis. Strain measurements were taken at ten locations across each Axial strap and 5 locations across each Hoop strap, as seen in Figure 10 and Figure 16. Figure 25 shows the strain measurements at each of the locations on Axial strap 1. The plots for the other straps look similar to Figure 25. The strain is converted to load using the load vs. strain equations generated in the strap level testing (Section IIA and Figure 3) and the average load for the strap is calculated (Figure 26). Figure 27 shows the average load in each of the Axial straps (Axial straps 1, 3, 5, 7, 9), and the comparison to the predicted load. The analytical prediction is determined as described in Section III E. The curve labeled "burst prediction" is determined based on the typical average ultimate tensile strength seen in strap level tensile testing, and the hydrostatic burst pressure observed in previous burst tests of this same restraint layer design. The hoop strap plots shown in Figure 28 and Figure 29 were generated by the same process used for the axial straps.

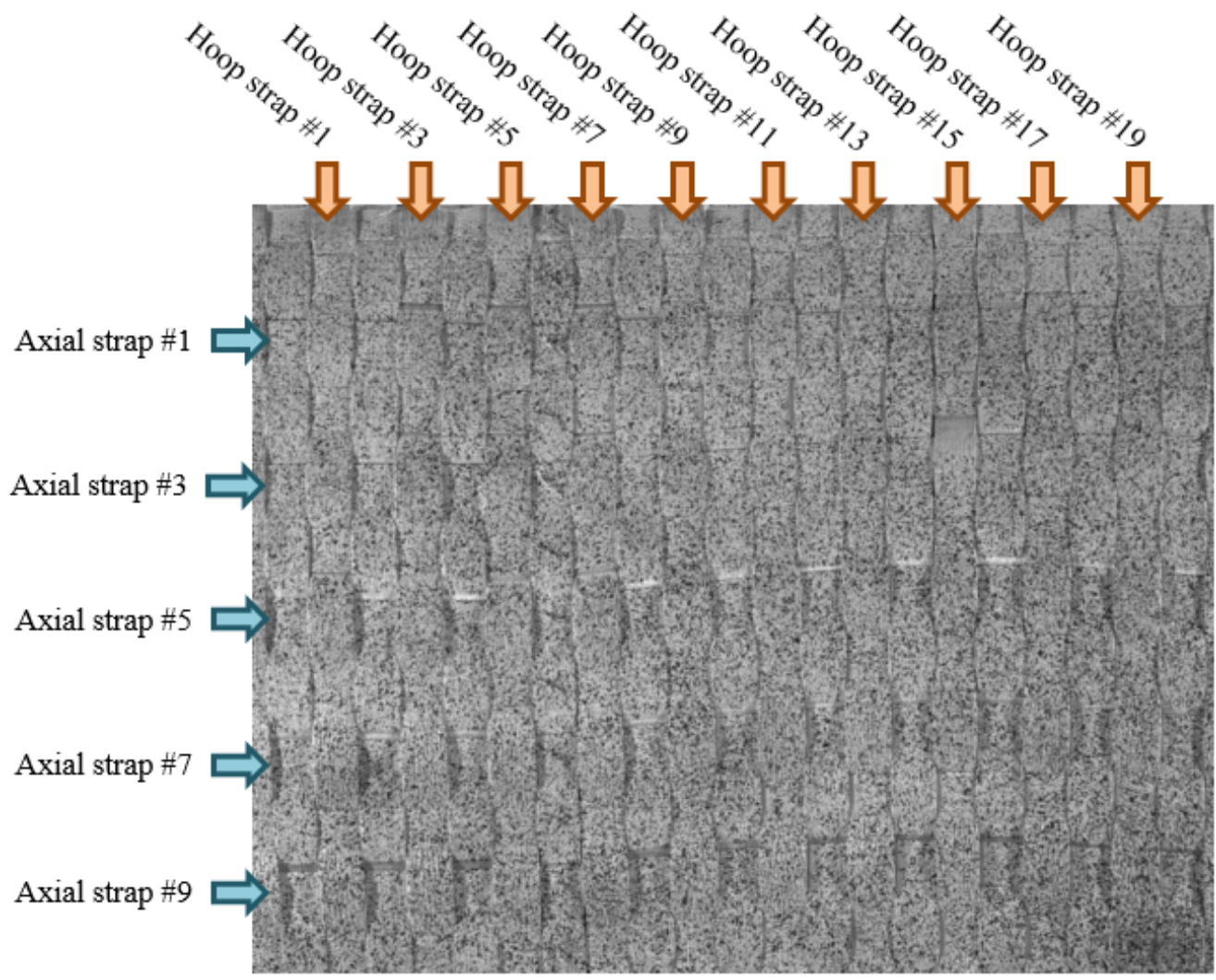

Figure 24. Location of Hoop Straps and Axial Straps measured 


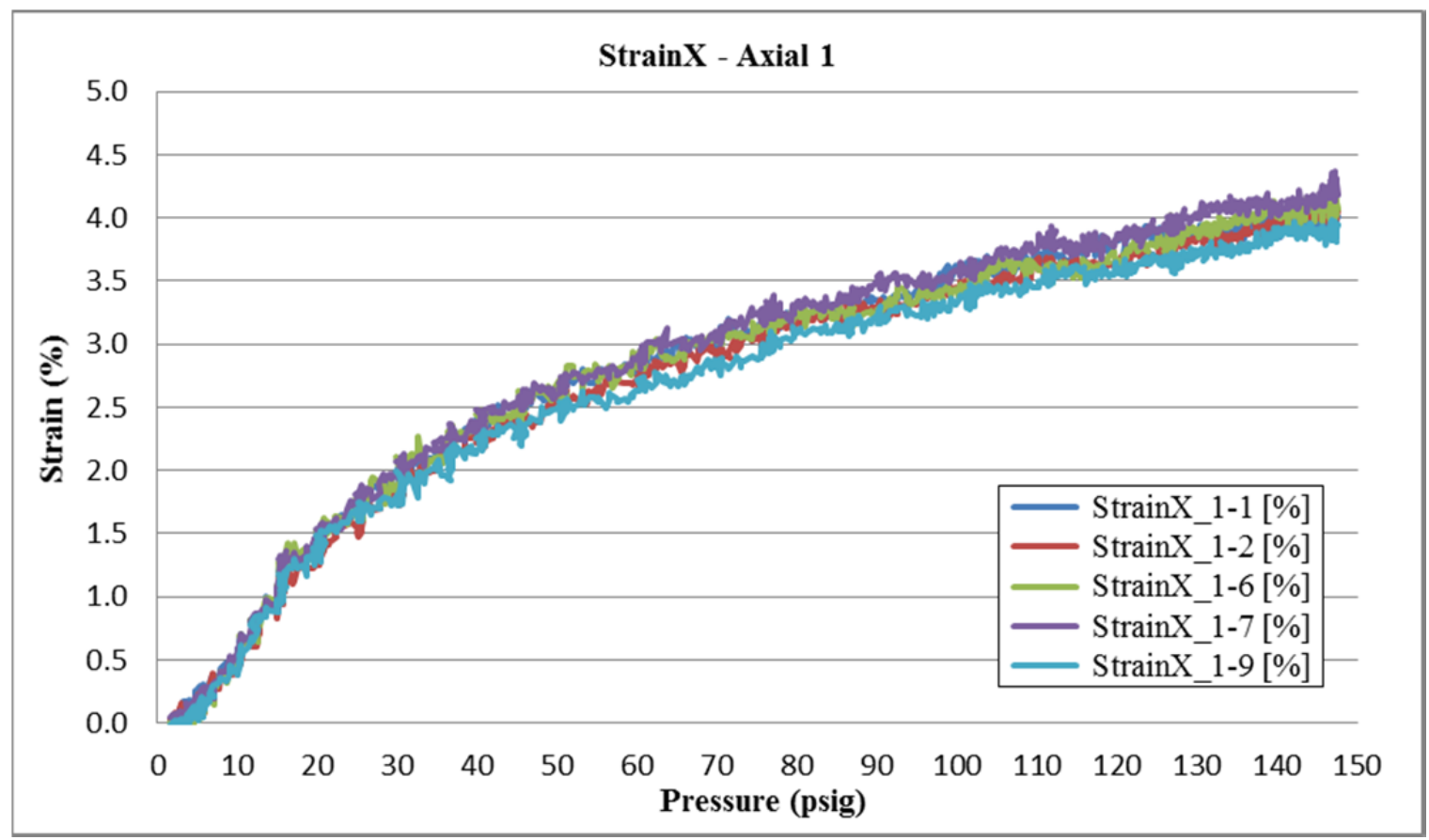

Figure 25. Strain on Axial Strap 1.

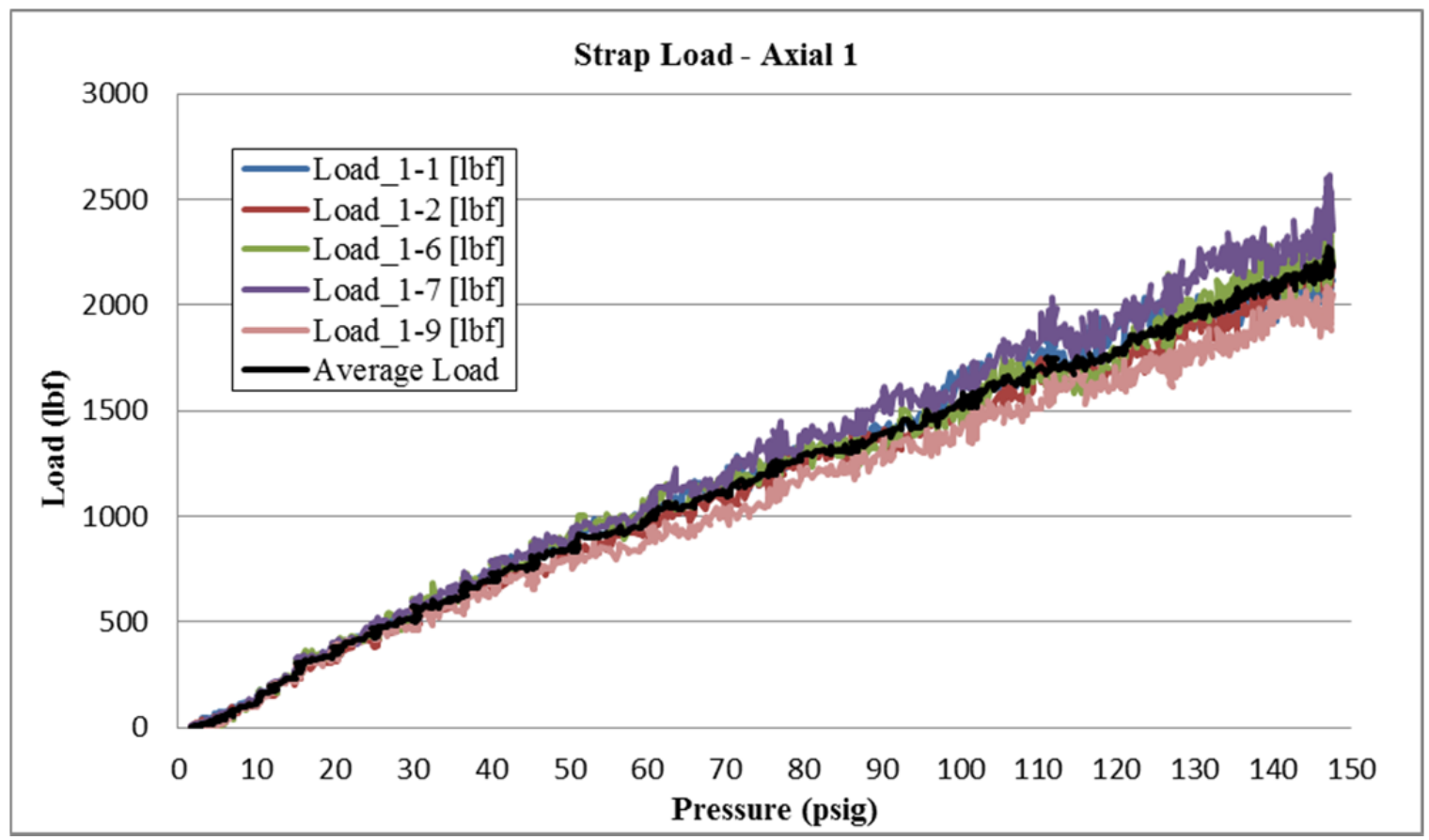

Figure 26. Load on Axial Strap 1. 


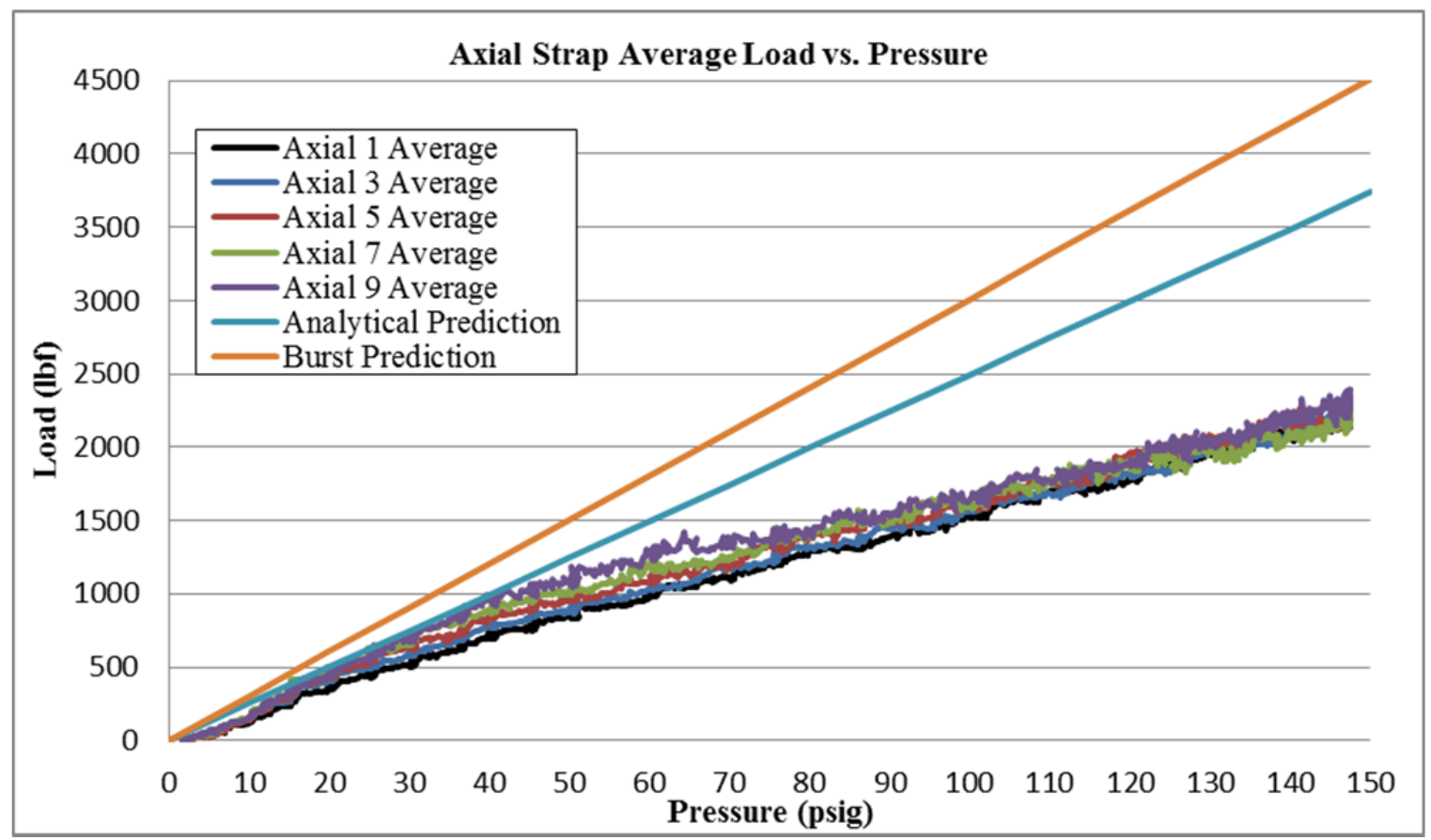

Figure 27. Axial Strap Average Load vs. Pressure.

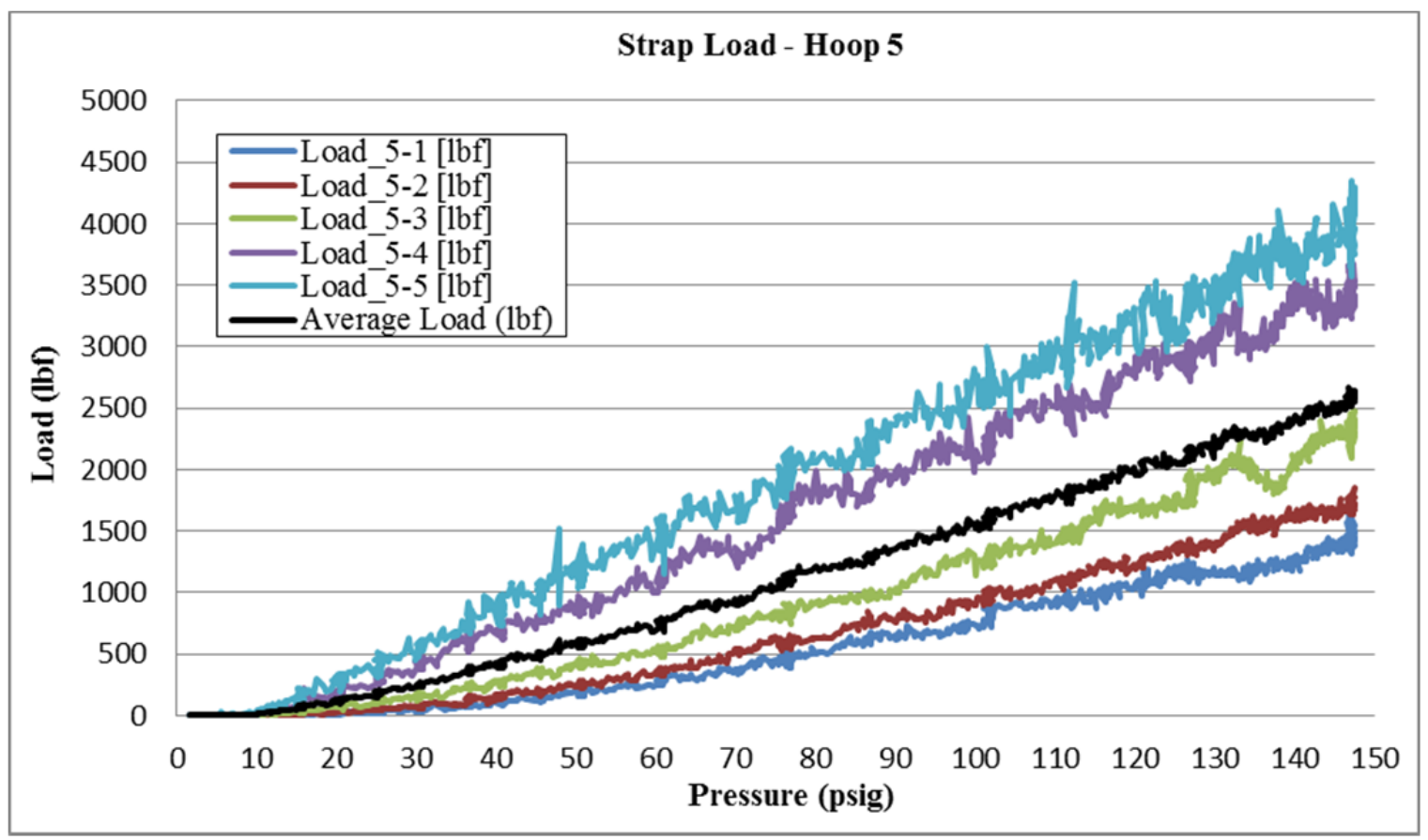

Figure 28. Strain on Hoop Strap 5. 


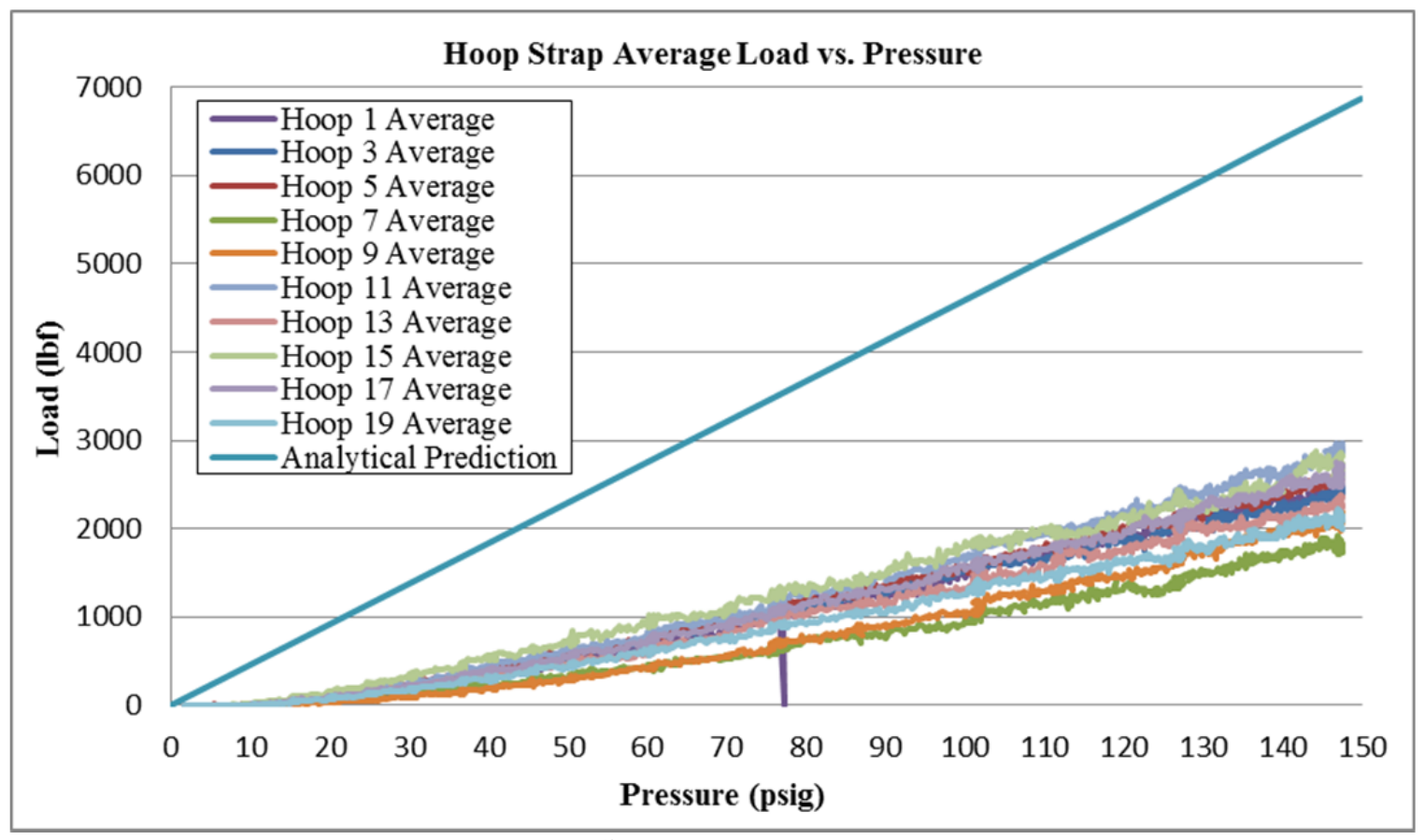

Figure 29. Hoop Strap Average Load vs. Pressure. 


\section{Conclusions}

The strap load data obtained from Photogrammetry measurements falls below the prediction curves for both the axial straps and the hoop straps. This is consistent with observations from previous tests. More work is necessary to perfect the technique of photogrammetry on tightly woven softgoods, to identify alternate means of measuring the strap load without disturbing the restraint configuration, and to develop more accurate analytical methods.

The creep burst test produced a wealth of structural dynamics data that will continue to be studied for insights into the structural health of inflatable structures.

When the module level creep results are plotted with the strap level creep results, the effects of the multi-strap architecture are observed. Figure 30 is a plot of Creep life versus percent of ultimate loading for $6,000 \mathrm{lb} /$ in (shown in green) and 12,500 lb/in (shown in red) for Vectran webbing procured by NASA. The vertical axis shows the percent of ultimate strength and the horizontal axis shows time-to-failure on a log-scale. Also shown (black dot) is where the 88 -inch diameter inflatable module burst.

Based on prior tests and analysis, it was determined that the first failure mode of the assembled module was in one of the $6,000 \mathrm{lb} /$ in structural webbings. For the $6,000 \mathrm{lb} /$ in webbings there is a large failure range for webbings loaded between $60 \%$ and $90 \%$ of ultimate. That range is bound by the two dashed green lines and projected for longer durations. The black line is drawn through the point where the test article failed and parallel to the dashed green lines that bound $6,000 \mathrm{lb} /$ in webbing failures.

For a small inflatable where it is easier to put larger margins on the structural restraint layer, such as operating in the $10 \%$ range, certifying for a two-year life with a factor of four is possible. For a larger inflatable module (22-foot diameter; BA 330 or TransHab class) that may be operating closer to the $25 \%$ range, as was the case for TransHab, certifying for a 2-year life with a factor of four also appears manageable. However, certifying for a 10-year life with a factor of four is more concerning when additional knock-down factors and end-of-life properties are included. It is worth noting that these data presented utilized NASA-procured Vectran straps and the assembled article was for a NASA woven design. For a BA 330 article, Bigelow Aerospace will have their own creep life certification program, utilizing their own structural members and assembled configuration, although these types of data may help support that program.

Further work is necessary to define the creep relationship of the webbing at lower loads. A small number of webbing samples remain under load at NASA Langley Research Center in a longer term test program. An accurate means of accelerating creep behavior is required to assess creep behavior over the long term, and to evaluate the effects of various module design characteristics and potential knockdowns such as stitched seams, indexing, environmental effects, and physical damage. Additional module level testing is desirable in order to investigate the effects of the module architecture on the creep performance at other load levels.

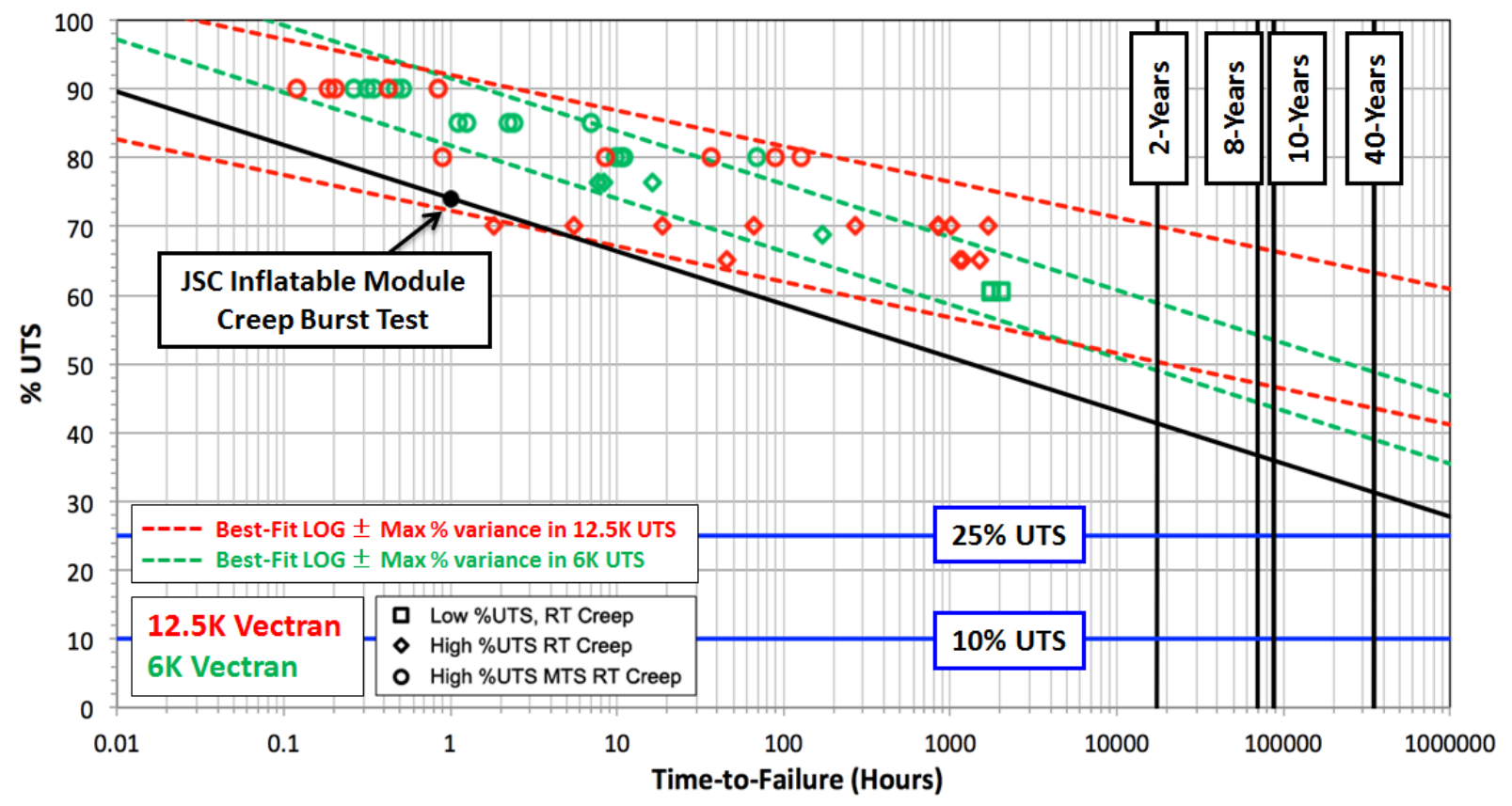

Figure 30. Vectran creep curve projections.

22

American Institute of Aeronautics and Astronautics 


\section{References}

${ }^{1}$ Jasen L. Raboin et. al., "Inflatable Vessel and Method”, US patent No. US 6,547,189 B1, April 15, 2003

${ }^{2}$ Vectran Engineering Data, Celanese Acetate LLC, From website Accessed October 29, 2014, http://www.swicofil.com/vectranengineering.pdf.

${ }^{3}$ Russell B. Fette and Marjorie F. Sovinski, "Vectran Fiber Time-Dependent Behavior and Additional Static Loading Properties", NASA/TM-2004-212773, Dec. 2004.

${ }^{4}$ Tom C. Jones and William R. Doggett, "Time-Dependent Behavior of High-Strength Kevlar and Vectran Webbing”, 55th AIAA Structures, Structural Dynamics, and Materials Conference, National Harbor, Maryland, Jan. 13-17 2014.

${ }^{5}$ de la Fuente, Raboin, et. al., "TransHab: NASA's Large-Scale Inflatable Spacecraft", 2000 AIAA Space Inflatables Forum, Atlanta, GA, April 3-6 2000.

${ }^{6}$ Robert T. Bigelow and Brian Aiken, "Flexible Structural Restraint Layer for Use with An Inflatable Module Structure", US patent No. US 7,100,874 B2, Sept. 5, 2006

${ }^{7}$ Jones, Thomas C., Doggett, William R., Stanfield, Clarence E., "Accelerated Creep Testing of High Strength Aramid Webbing," AIAA Paper 2012-1771, NF1676L-13173, 53rd AIAA/ASME/ASCE/AHS/ASC Structures, Structural Dynamics and Materials Conference; 23-26 Apr. 2012; Honolulu, HI; United States.

${ }^{8}$ Military Specification (MIL)-T-87130, Tape and Webbing, Textile, Para-Aramid, Intermediate Modulus, USAF, Amendment 2 (USAF, 6 April 1981).

${ }^{9}$ J.E. Edgecombe, H. M. de la Fuente, and G.D. Valle, "Damage Tolerance Testing of a NASA TransHab Derivative Woven Inflatable Module", 2009 AIAA/ASME/ASCE/AHS/ASC Structures, Structural Dynamics, and Materials Conference, AIAA-2009-2167.

${ }^{10} \mathrm{GOM} \mathrm{mbH}$, ARAMIS v6.1 User Manual. Braunschweig, Germany, 2009.

${ }^{11}$ George James, et. al., "Operational Analysis in the Launch Environment", Proceedings of the $30^{\text {th }}$ International Modal Analysis Conference, Jacksonville, FL, January 30 - February 2, 2012.

${ }^{12}$ George James, et. al., "Analysis of Accelerometer Data from a Woven Inflatable Creep Burst Test", Proceedings of the $56^{\text {th }}$ AIAA/ASME/ASCE/AHS/ASC Structures, Structural Dynamics, and Materials Conference, January 5-9, 2015.

${ }^{13}$ Michael Grygier, "Modal Test Technology as Non-Destructive Evaluation of Space Shuttle Structures," NASA CP3263, 1994, pp. 329-334, NASA-JSC, Houston, TX, January, 1987.

${ }^{14}$ Tim Cao, et. al., "Identification of Ritz Vectors from Ambient Test Data," Proceedings of the $16^{\text {th }}$ International Modal Analysis Conference, Santa Barbara, CA, February 2-5, 1998.

${ }^{15}$ George James, et. al., "Reconstruction of the Space Shuttle Roll-Out Forcing Function", Proceedings of the $25^{\text {th }}$ International Modal Analysis Conference, Orlando, FL, February 19-23, 2007. 